\title{
Padrões Setoriais de Inovação da Indústria de Transformação Brasileira
}

\section{Conceição de Fátima Silva}

Professora - Fundação Educacional Inaciana (FEI) Departamento de Adm. de Empresas

Endereço: Rua Tamandaré, 688 - São Paulo - SP - Brasil - CEP: 01525-000

E-mail: concva@fei.edu.br

\author{
Wilson Suzigan \\ Professor - Departamento de Política Científica e Tecnológica (Unicamp) \\ Instituto de Geociências - Caixa Postal 6152 - CEP: 13083-970 - Campinas - SP - Brasil \\ E-mail: wsuzigan@ige.unicamp.br
}

Recebido em 14 de agosto de 2012. Aceito em 19 de dezembro de 2013.

\section{Resumo}

O artigo investiga os padrões setoriais de inovação da indústria de transformação brasileira a partir do referencial teórico da Escola Evolucionária Neo-Schumpeteriana, da base de dados da Pesquisa de Inovação Tecnológica (PINTEC) para o período 2006-2008 e de duas hipóteses norteadoras. A primeira sugere que a realidade concorrencial molda a estratégia competitiva das empresas e, por decorrência, a rotina e o padrão de busca destas. A segunda é de que há convergência entre o comportamento inovativo da indústria nacional e a taxonomia proposta por Keith Pavitt. Os resultados corroboram as duas hipóteses. No entanto, foi também identificado que setores que conciliam baixa densidade tecnológica e elevada participação das exportações na geração da receita apresentam baixa aderência às suas respectivas categorias pavittianas.

\section{Palavras-Chave}

inovação tecnológica, padrões setoriais, indústria de transformação PINTEC

\begin{abstract}
This paper investigates sectoral patterns of innovation in the Brazilian manufacturing industry under the Neo-Schumpeterian Evolutionary approach. The database used is the Brazilian Survey of Technological Innovation (PINTEC) for 2006-2008. Two hypotheses guide the paper. The first suggests that the competitive reality shapes the competitive strategy of firms and, consequently, their routine search pattern. The second assumes that there is a convergence between the innovative behavior of the domestic industry and the taxonomy proposed by Keith Pavitt. The results support the two hypotheses. However, the paper also points out that sectors that combine low-tech and high share of exports in revenue have low adherence to their respective Pavittians types.
\end{abstract}

\section{Keywords}

technological innovation, sectoral patterns, manufacturing industry, PINTEC

\section{JEL Classification}

031 


\section{Introdução}

O presente artigo avalia os padrões setoriais de inovação da indústria de transformação brasileira a partir de dados $^{1}$ selecionados da Pesquisa de Inovação Tecnológica (PINTEC) para o período 20062008, complementados por indicadores de estrutura e desempenho econômico produzidos pela Pesquisa Industrial Anual (PIA) e pela Secretaria de Comércio Exterior (SECEX), estas últimas do ano de 2008.

A hipótese fundamental tem sua origem na Escola Evolucionária Neo-Schumpeteriana e sugere que as idiossincrasias tecnológicas e econômicas que permeiam os diferentes setores da economia ocasionam estratégias competitivas distintas e, consequentemente, revelam padrões de comportamento setoriais. No tocante às condutas inovativas, definem se o esforço para a inovação concentra-se em produto ou processo, se o foco das inovações está na ampliação de mercado, redução de custos ou melhoria de produtos, se as fontes prioritárias de inovação são internas ou externas, bem como tipificam as formas de aprendizagem e produção do conhecimento. Portanto, definir padrões setoriais de inovação consiste em identificar condutas inovativas que revelem uniformidade entre empresas de um mesmo setor e, simultaneamente, distingam e assemelhem os setores entre si, o que resulta em categorias semelhantes, tal como proposto por Keith Pavitt.

O objetivo de agrupar os setores da indústria segundo a tipologia do comportamento inovativo e a amplitude do conjunto de variáveis analisadas determinaram a técnica estatística de cluster (aglomeração) para o tratamento e análise dos dados.

O artigo está estruturado em 5 seções incluindo esta introdução. $\mathrm{Na}$ segunda estão expostos os norteadores teóricos e metodológicos que orientaram a pesquisa e definiram o tratamento dos dados. Na sequência, a terceira seção exibe as análises de clusters realizadas para os indicadores de 'Estrutura e desempenho econômico', 'Esforços inovativos', 'Resultados inovativos', 'Fontes de informação', 'Fontes de inovação', 'Interatividade' e 'Trajetórias tecnológicas'. Na quarta, os resultados parciais, apresentados na seção 3, são consolidados para definição do perfil inovativo dos diferentes setores da indústria

\footnotetext{
1 Não foram utilizados os microdados da PINTEC.
} 
de transformação nacional. Nesta seção, merece destaque a reduzida aderência de setores que conjugam baixa densidade tecnológica (BDT), elevados desempenho exportador e concentração econômica. $\mathrm{Na}$ quinta e última seção são sintetizados os principais resultados obtidos ao longo do trabalho.

\section{Aspectos Metodológicos}

O perfil inovativo das empresas nacionais foi elaborado através de 53 indicadores, agrupados em 7 categorias distintas e calculados a partir da seleção de 48 variáveis da base de dados da PINTEC 2008, 4 da PIA 2008 e 1 da SECEX. A escolha das variáveis, bem como a definição dos indicadores e seus respectivos agrupamentos foi inspirada no referencial teórico da Escola Evolucionária Neo-Schumpeteriana (EENS), particularmente, na taxonomia proposta por Pavitt (1984), Dosi; Pavitt; Soete (1990) e Malerba (1992).

A primeira categoria reúne os indicadores de características econômicas, utilizados com o objetivo de avaliar a influência dessas características no comportamento inovativo da indústria. Destes, os dois primeiros indicadores (concentração e tamanho médio) dizem respeito à estrutura industrial, e são decorrentes da ênfase dada por Schumpeter (1943) ao tamanho das firmas na definição de seu comportamento tecnológico. Adicionalmente, remetem aos testes empíricos de Pavitt (1984), Cohen; Florida; Goe (1994) e Archibugi; Cesaratto; Sirilli (1991). Aqui, vale salientar que estes indicadores carregam um problema implícito, pois naqueles setores em que é grande o número de empresas, mas é pequeno o daquelas representativas na geração do produto setorial, ou seja, setores nos quais é grande a concentração econômica, o tamanho médio não reflete a realidade estrutural do setor e os indicadores de comportamento acabam por não retratar a efetiva atuação do grupo de empresas que determinam o desempenho setorial. Caso de 'Metalurgia básica', 'Veículos' e 'Máquinas e materiais elétricos'.

Os dois indicadores seguintes tratam do desempenho exportador e da produtividade da mão de obra. A contribuição das exportações na geração da receita setorial visa a avaliar se a exposição à concorrência internacional é variável relevante na determinação das condutas inovativas adotadas pelos diferentes setores. 
A razão para fazê-lo está na premissa adotada pela EENS de que o desempenho exportador decorre da performance inovativa (Freeman, 1982). Nesse sentido, os setores mais propensos à exportação seriam também setores mais competitivos e inovadores. Adicionalmente, a competitividade está relacionada com a eficiência econômica. Logo, setores mais competitivos são também setores mais eficientes. Assim, com o objetivo de captar a influência da eficiência econômica na determinação do comportamento inovativo, foi elaborado o indicador de produtividade da mão de obra.

Quadro 1 - Indicadores econômicos e inovativos

\begin{tabular}{|c|c|c|}
\hline \multicolumn{3}{|c|}{ Indicador / Descrição } \\
\hline \multirow{4}{*}{ 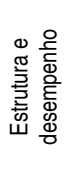 } & \multicolumn{2}{|l|}{ Concentração: razão entre o pessoal ocupado nas 12 maiores empresas e o total de empregos do setor } \\
\hline & \multicolumn{2}{|l|}{ Tamanho médio: total de empregos dividido pelo número de estabelecimentos do setor } \\
\hline & \multicolumn{2}{|l|}{ Intensidade das exportações: total de exportações do setor dividido pela receita líquida } \\
\hline & \multicolumn{2}{|l|}{ Produtividade da mão de obra: total da receita líquida dividido pelo número de trabalhadores } \\
\hline \multirow{5}{*}{ 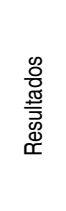 } & \multicolumn{2}{|l|}{ Taxa efetiva de inovação: empresas que fizeram inovações de produto e/ou processo para o mercado. } \\
\hline & \multicolumn{2}{|l|}{ Taxa efetiva de inovação em produtos: empresas que fizeram inovações de produto para o mercado. } \\
\hline & \multicolumn{2}{|c|}{ Taxa efetiva de inovação em processos: empresas que fizeram inovações de processo para o mercado. } \\
\hline & \multicolumn{2}{|c|}{ Taxa de inovações radicais em produto: empresas que introduziram produtos novos para o mercado mundial. } \\
\hline & \multicolumn{2}{|c|}{ Taxa de inovações radicais em processo: empresas que introduziram processos novos para o mercado mundial. } \\
\hline \multirow{5}{*}{ 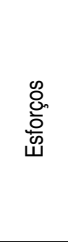 } & \multicolumn{2}{|c|}{ Gastos em atividades inovativas: proporção de empresas que realizaram gastos em atividades inovativas. } \\
\hline & \multicolumn{2}{|c|}{ Atividades internas e contínuas de P\&D: proporção de empresas com atividades internas e contínuas de P\&D. } \\
\hline & \multicolumn{2}{|l|}{ Grau de interatividade: proporção de empresas com relações de cooperação com outras organizações. } \\
\hline & \multicolumn{2}{|l|}{ Grau do esforço inovador: Proporção dos gastos em atividades inovativas na receita líquida de vendas. } \\
\hline & \multicolumn{2}{|c|}{$\begin{array}{l}\text { Utilização de recursos públicos: proporção de empresas que utilizaram recursos públicos nas atividades } \\
\text { inovativas. }\end{array}$} \\
\hline \multirow{13}{*}{ 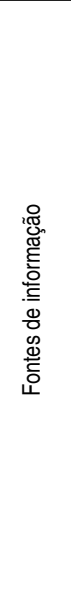 } & P\& interna & \multirow{13}{*}{ 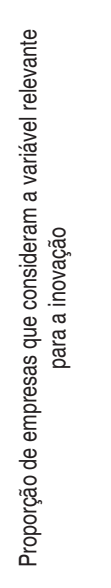 } \\
\hline & Outras áreas da empresa & \\
\hline & Centros de capacitação profissional e assistência técnica & \\
\hline & Empresas de consultorias e consultores independentes & \\
\hline & Conferências, encontros e publicações especializadas & \\
\hline & Concorrentes & \\
\hline & Relevância de feiras e exposições & \\
\hline & Relevância dos fornecedores & \\
\hline & Clientes ou consumidores & \\
\hline & Redes de informação informatizadas & \\
\hline & Institutos de pesquisa e centros tecnológicos & \\
\hline & Universidades & \\
\hline & $\begin{array}{l}\text { Instituições de testes, ensaios e certificações: proporção de empresas que consideram as } \\
\text { variáveis relevantes para a inovação }\end{array}$ & \\
\hline
\end{tabular}


(Continuação)

\begin{tabular}{|c|c|c|}
\hline \multirow{9}{*}{ 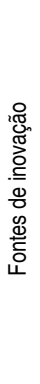 } & \multicolumn{2}{|c|}{ Autonomia tecnológica: Razão entre os gastos em atividades inovativas internas e aquisições externas } \\
\hline & P\&D interna & \multirow{8}{*}{ 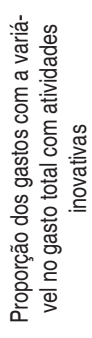 } \\
\hline & Marketing & \\
\hline & Treinamento & \\
\hline & Projeto industrial e outras preparações técnicas & \\
\hline & Software & \\
\hline & P\&D externa & \\
\hline & Máquinas e equipamentos & \\
\hline & Outros conhecimentos externos & \\
\hline \multirow{7}{*}{ 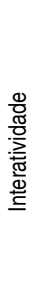 } & Clientes ou consumidores & \multirow{7}{*}{ 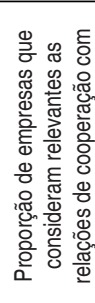 } \\
\hline & Fornecedores & \\
\hline & Concorrentes & \\
\hline & Universidades e institutos de pesquisa & \\
\hline & Centros de capacitação e assistência técnica & \\
\hline & Instituições de testes, ensaios e certificações & \\
\hline & Consultoria e consultores independentes & \\
\hline \multirow{10}{*}{ 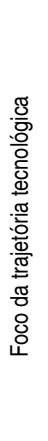 } & Melhoria da qualidade dos produtos & \multirow{10}{*}{ 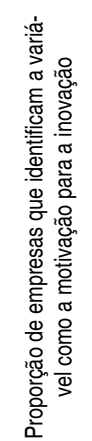 } \\
\hline & Ampliação da gama de produtos ofertados & \\
\hline & Manutenção da participação da empresa no mercado & \\
\hline & Ampliação da participação da empresa no mercado & \\
\hline & Abertura de novos mercados & \\
\hline & Aumento da capacidade produtiva & \\
\hline & Flexibilidade da produção & \\
\hline & Redução dos custos de produção & \\
\hline & Redução do impacto ambiental e/ou em aspectos ligados à saúde e segurança & \\
\hline & Enquadramento em regulações e normas padrão & \\
\hline
\end{tabular}

Fonte:IBGE,PINTEC 2008,PIA2008 e SECEX/MDIC/ALICE/SISCOMEX(elaboraçãoprópria).

Os indicadores de 'Resultados' são dedicados à captação do perfil das inovações introduzidas pelas empresas. Quanto ao tipo, as inovações podem ser de produto ou processo. Quanto ao grau de inovatividade elas podem ser efetivas ${ }^{2}$ no sentido de que representam inovações para o mercado ou inovações radicais, pois representam uma novidade para o mercado mundial.

2 Busca-se, através do indicador de efetividade das inovações, retomar a concepção de que a inovação tecnológica é, por definição, a introdução de um produto ou processo novo para o mercado. Logo, as inserções de produtos ou processos novos apenas para a empresa não consistem em inovações efetivas. 
As inovações para o mercado mundial têm impactos não apenas locais e podem provocar mudanças substantivas no comportamento do mercado. Por esta razão, são classificadas como inovações radicais.

Para a apreensão dos 'Esforços inovativos' empreendidos pela indústria foram identificadas a existência de gastos em atividades inovativas, de atividades internas de $\mathrm{P} \& \mathrm{D}$ e relações de cooperação com outras organizações. Adicionalmente, foram apontados o volume de recursos gastos nas atividades inovativas e a contribuição dos recursos públicos para a ocorrência desses gastos. Em seu conjunto, tais indicadores medem a intensidade dos esforços tecnológicos setoriais, bem como a capacidade que os diferentes setores têm de extrair benefícios financeiros dos esforços públicos.

As duas categorias seguintes contemplam as diferentes formas de aprendizagem empregadas pelas firmas, assim como a absorção do conhecimento. No primeiro grupo estão os indicadores das fontes de informação que as empresas utilizam e consideram relevantes ${ }^{3}$ para suas inovações. No grupo seguinte são apresentados os indicadores das fontes de inovação, entendidas aqui como a destinação dos gastos empenhados nas atividades inovativas. Tais indicadores, assim como os das fontes de informação, podem ser divididos em dois grupos, quais sejam fontes internas e externas, e a relação entre os gastos com estas fontes é, por definição, o grau de autonomia tecnológica.

No sexto grupo estão elencados os indicadores que buscam apreender o padrão interativo setorial. A partir da informação da existência e relevância de relações cooperativas para as inovações realizadas pelas empresas é possível identificar em que medida e quais interações contribuem para os resultados inovativos. Juntamente com as fontes de informação e inovação, as relações interativas revelam o padrão setorial de absorção do conhecimento (Malerba, 1992).

3 Foram consideradas relevantes as fontes classificadas pelas empresas como de alta ou média importância para o processo inovativo conforme Cohen; Nelson; Walsh, 2002. 
Nesse sentido, as empresas podem aprender buscando (P\&D interna), ${ }^{4}$ fazendo (outras áreas internas), usando (softwares e máquinas e equipamentos) e interagindo (fornecedores, clientes/consumidores, concorrentes, feiras e exposições, empresas de consultorias, centros de capacitação, institutos de pesquisa e universidades). Por último, os indicadores de 'Trajetória tecnológica' revelam os impactos produzidos pelas inovações implementadas pelas empresas e visam a identificar o foco da trajetória tecnológica setorial, ou seja, a motivação para a inovação que pode estar associada ao produto, ao mercado, ao processo, aos aspectos relacionados ao meio ambiente, à saúde e segurança, ou ao enquadramento em regulamentações e normas. Juntas, estas motivações revelam a razão para as empresas assumirem os riscos da inovação.

Partindo da metodologia de Pavitt (1984), cuja base de dados envolveu exclusivamente as empresas mais inovadoras do Reino Unido, de Mansfield e Lee (1996), da Yale Survey on Industrial on Industrial Research and Development de $1984^{5}$ e da Carnegie Mellon Survey on the Nature and Determinants of Industrial Research and Development de 1994, ${ }^{6}$ cujos entrevistados foram os dirigentes de áreas de P\&D (portanto, com atuação inovativa) de indústrias dos Estados Unidos, foram selecionados os dados, exclusivamente, das empresas inovadoras ${ }^{7}$ da indústria de transformação nacional, segundo a nomenclatura da PINTEC, ou seja, aquelas que implementaram produto e/ou processo novo ou substancialmente aprimorado, mesmo que novo ou substancialmente aprimorado exclusivamente para a própria empresa.

4 Os tipos de aprendizado propostos por Malerba (1992) resultam numa taxonomia de 6 padrões distintos, quais sejam: (a) Learning by doing, internal to the firm and related to production activity; (b) Learning by using, internal to the firm and related to the use of products, machinery and inputs; (c) Learning from advances in science and technology, external to the firm and related to the absorption of new developments in science and technology; (d) Learning from inter-industry spillovers, external to the firm and related to what competitors and other firms in the industry are doing; (e) Learning by interacting, external to the firm and related either to the interaction with upstream or downstream sources of knowledge such as suppliers or users or to the cooperation with other firms in the industry; (f) Learning by searching, internal to the firm and related (mainly) to formalized activities (such as R-D) aimed at generating new knowledge (Malerba, 1992, p.848).

5 Os resultados das entrevistas realizadas pela Yale Survey on Industrial Research and Development são aqui apresentados por Klevorick et al. (1995) e Levin et al. (1987).

6 Os resultados das entrevistas realizadas pela Carnegie Mellon Survey on the Nature and Determinants of Industrial Research and Development são aqui abordados por Cohen e Walsh (2000), Cohen; Florida; Goe (1994), Cohen; Nelson; Walsh (2000), Florida e Cohen (1999) e Cohen; Nelson; Walsh (2002).

7 Ao considerar apenas as empresas inovadoras, buscou-se manter o foco da análise restrito ao padrão de comportamento das empresas que inovam, evitando, portanto, incorrer na comparação destas com o conjunto da indústria de transformação. 
A elevada quantidade de indicadores e variáveis selecionadas decorre da percepção de não linearidade do comportamento dos diferentes setores da indústria de transformação. Em outras palavras, a restrição do número de variáveis empobreceria a análise na medida em que mascararia a diversidade intersetorial. Adicionalmente, a amplitude do conjunto de variáveis a serem analisadas e o objetivo de agrupar os setores segundo a tipologia do comportamento inovativo determinou a utilização das técnicas estatísticas de cluster (aglomeração) para o tratamento e análise dos dados.

\subsection{Análise de Cluster}

A análise de cluster envolve o conjunto de técnicas estatísticas que tem por objetivo "encontrar e separar objetos em grupos similares" (Bussab et al., 1990). Dada uma amostra de $n$ objetos (setores da indústria de transformação no presente estudo), cada um deles caracterizado por $v$ variáveis (condutas inovativas), o problema da análise de cluster é encontrar um esquema de classificação que agrupe os objetos (setores) em $g$ grupos. No presente caso, a análise de cluster visa ao agrupamento dos diferentes setores da indústria de transformação a partir, numa primeira etapa, das suas características econômicas e, nas etapas seguintes, das condutas inovativas compartilhadas entre eles.

Considerando que o objetivo da análise de cluster é distribuir elementos, ou casos, em grupos homogêneos e distintos entre si (clusters), o primeiro problema da análise é definir alguma medida de similaridade, ou proximidade. Para atender a esta necessidade, a medida de similaridade mais usada para a formação de cluster é a distância Euclidiana. ${ }^{8}$

A distância euclidiana entre dois casos $i$ e $j$ caracterizados por $k$ variáveis é:

$$
D_{i j}=\sqrt{\left(X_{1 i}-X_{1 j}\right)^{2}+\left(X_{2 i}-X_{2 j}\right)^{2}+\ldots+\left(X_{k i}-X_{k j}\right)^{2}}
$$

8 Para uma apresentação de outras medidas de similaridade ver Hair et al. (1998). 
O método de $K$ médias ( $K$-means) distribui os casos em $k$ clusters $(k$ é pré-determinado), cujas características ainda não são conhecidas. $\mathrm{O}$ algoritmo desse método atribui um caso a um cluster minimizando a distância do caso à média do cluster. A média do cluster, ou centroide, é a média dos valores de cada variável considerada. Usando a notação acima, o centroide é formado por $k$ coordenadas $z$ :

$$
z_{1}=\frac{X_{1 i}+X_{1 j}}{2} ; z_{2}=\frac{X_{2 i}+X_{2 j}}{2} ; \cdots z_{k}=\frac{X_{k i}+X_{k j}}{2}
$$

Este processo é iterativo, sendo que em cada iteração são calculadas as médias dos clusters. O algoritmo dá por encerrado o trabalho quando não há mais diferenças entre as médias de duas iterações. Isto implica nova realocação de casos que tornaria os clusters internamente menos homogêneos e externamente mais homogêneos. A análise da variância (ANOVA) indica quais são as variáveis que melhor contribuem para a formação dos clusters. A média dos clusters finais, ou centroides são as médias de cada variável associada aos elementos que pertencem aos respectivos clusters. A distância Euclidiana entre os centroides indica a similitude entre os clusters. Quanto maior a Distância Euclidiana, mais heterogêneos são os clusters. O R-quadrado, por sua vez, mede a porcentagem da variabilidade total que é retida em cada uma das soluções dos clusters. E para tratamento e análise dos dados quantitativos, utilizou-se o pacote estatístico Statistical Package for the Social Sciences (SPSS).

\section{Tipologia Econômica e Condutas Inovativas}

Padrões setoriais de inovação resultam das diferenças intersetoriais de condutas inovativas que, por sua vez, decorrem das características tecnológicas e econômicas que distinguem os setores da economia. Dentre outras qualidades, tais características determinam que as inovações sejam concentradas em produto ou processo, que o esforço interativo ocorra e com quais organizações, que o processo de absorção do conhecimento seja ativo ou passivo, quais são as fontes de informação e inovação relevantes e quais as motivações para a mudança tecnológica (Pavitt, 1984 e Malerba, 1992). 
Guardados estes pressupostos, definir os padrões setoriais de inovação consiste em identificar condutas que assemelham empresas de um mesmo setor e, simultaneamente, que distingam um setor dos outros, ou seja, estabelecer as características de funcionamento e idiossincrasias dos sistemas setoriais de inovação. Para tanto, empreendeu-se a análise de cluster das condutas a partir de 6 blocos de indicadores do comportamento inovativo. Adicionalmente, o comportamento inovativo foi comparado com os clusters estabelecidos pelos indicadores de estrutura e desempenho econômico para captar a influência destes na formatação dos padrões setoriais de inovação.

\subsection{Estrutura e Desempenho Econômico}

Segundo a EENS, a realidade concorrencial molda a estratégia competitiva e, por decorrência, as condutas inovativas das empresas (Nelson e Winter, 1982). Tendo em vista esta premissa, a presente análise de cluster busca, a partir de um conjunto restrito de indicadores (concentração, tamanho médio, produtividade e propensão exportadora), configurar o padrão concorrencial dos diferentes setores da indústria de transformação nacional.

A Tabela 1 apresenta a análise de cluster elaborada a partir dos 4 indicadores de estrutura e desempenho, em que é possível observar que há diferenças marcantes entre os setores e entre os clusters. E diferenças marcantes ocasionam a concentração que caracteriza a composição dos clusters na tabela em questão, são 6 setores distribuídos em 2 clusters e os demais (16) nos outros 2. Com um R-quadrado geral de $74,9 \%$ é possível afirmar que a composição dos clusters de estrutura e desempenho é satisfatoriamente explicada pela variância dos indicadores selecionados. O cluster A tem como traços distintivos a elevada concentração de mercado e a também elevada relevância das exportações na geração de receita; em ambos os indicadores os resultados do cluster são muito superiores aos dos outros. Some-se a isto que a produtividade da mão de obra, bem como o tamanho médio das empresas, é significativamente superior à média da indústria de transformação e o cluster pode ser caracterizado pelo alto desempenho em todos os indicadores apontados. Já o cluster B é formado por setores em que a concentração de mercado também é elevada. No entanto, o destaque aqui é o fato das empresas serem muito grandes e 
exportarem pouco, características que distinguem este cluster dos demais. No cluster $C$, à exceção do desempenho exportador que é superior ao do cluster B, todos os outros indicadores situam-se abaixo dos outros clusters. Logo, é possível afirmar que o agrupamento é composto por setores em que é baixa a concentração e a produtividade da mão de obra, as empresas são pequenas, e as exportações são pouco relevantes para a geração da receita.

Finalmente, o cluster D apresenta desempenho mediano em todos os indicadores, exceto a propensão exportadora que é alta.

Tabela 1 - Análise de cluster I: Estrutura e desempenho

\begin{tabular}{|c|c|c|c|c|c|}
\hline 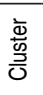 & Setor & CR-12 & $\begin{array}{l}\text { Número médio de } \\
\text { ocupações }\end{array}$ & $\begin{array}{c}\text { Produtividade } \\
\text { em R\$ }\end{array}$ & $\begin{array}{l}\text { Participação das } \\
\text { exportações na } \\
\text { receita }\end{array}$ \\
\hline \multirow{4}{*}{$\varangle$} & Metalurgia básica & 32,3 & 104,6 & 59.438 & 27,1 \\
\hline & Equipamentos de transporte & 58,8 & 136,8 & 34.985 & 46,1 \\
\hline & Produtos do fumo & 83,1 & 246,9 & 55.123 & 45,6 \\
\hline & Média do cluster & 58,1 & 162,8 & 49.849 & 39,6 \\
\hline \multirow{4}{*}{$\infty$} & Farmoquímicos e farmacêuticos & 25,3 & 160,0 & 31.643 & 6,5 \\
\hline & Coque, derivados do petróleo e biocombustíveis. & 55,2 & 821,3 & 79.547 & 6,8 \\
\hline & Fabricação de produtos químicos & 15,2 & 57,3 & 64.717 & 9,8 \\
\hline & Média do cluster & 31,9 & 346,2 & 58.636 & 7,7 \\
\hline \multirow{11}{*}{0} & Fabricação de produtos de metal & 5,2 & 27,9 & 13.028 & 6,3 \\
\hline & Confecção de artigos do vestuário e acessórios & 7,1 & 24,0 & 4.329 & 1,8 \\
\hline & Produtos de madeira & 8,1 & 25,3 & 8.253 & 28,7 \\
\hline & Móveis e indústrias diversas & 8,4 & 27,3 & 8.506 & 9,1 \\
\hline & Produtos de minerais não-metálicos & 8,6 & 29,3 & 12.939 & 7,7 \\
\hline & Impressão e reprodução de gravações & 9,3 & 17,8 & 10.464 & 2,1 \\
\hline & Artigos de borracha e plástico & 9,8 & 40,9 & 15.998 & 8,9 \\
\hline & Máquinas e equipamentos & 10,9 & 48,5 & 22.432 & 21,6 \\
\hline & Têxteis & 14,9 & 56,1 & 9.934 & 12,5 \\
\hline & Manutenção, rep. e inst. de máqs. e equipamentos ${ }^{9}$ & 18,9 & 31,7 & 8.900 & 0,0 \\
\hline & Média do cluster & 10,1 & 32,9 & 11.478 & 9,9 \\
\hline \multirow{7}{*}{ ๑ } & Celulose, papel e produtos de papel & 17,4 & 61,4 & 26.198 & 21,7 \\
\hline & $\begin{array}{l}\text { Prep. de couros e fab. de arts. de couro, artigos para } \\
\text { viagem e calçados }\end{array}$ & 23,9 & 50,0 & 6.275 & 30,1 \\
\hline & Equips. de informática, produtos eletrônicos e ópticos & 24,3 & 80,6 & 36.518 & 12,4 \\
\hline & Máquinas, aparelhos e materiais elétricos & 27,3 & 86,7 & 23.756 & 13,2 \\
\hline & Alimentos e bebidas & 27,5 & 64,8 & 21.465 & 19,3 \\
\hline & Veículos automotores, reboques e carrocerias & 28,8 & 135,5 & 42.598 & 15,0 \\
\hline & Média do cluster & 24,9 & 79,8 & 26.135 & 18,6 \\
\hline Indú & istria de transformação & 23,6 & 45,0 & 23.158 & 15,4 \\
\hline \multicolumn{3}{|c|}{ R-quadrado } & & \multicolumn{2}{|c|}{74,9} \\
\hline
\end{tabular}

Fontes: IBGE, PIA 2008 e SECEX/MDIC/ALICE/SISCOMEX (elaboração própria).

9 O setor de 'Manutenção' (divisão 33 da CNAE) compreende as atividades de manutenção, reparação e instalação de máquinas e equipamentos utilizados no processo de produção industrial, realizadas por unidades especializadas. 


\subsubsection{Esforços Inovativos}

Com um R-quadrado superior a $92 \%,{ }^{10}$ a análise de cluster apresentada na Tabela 2 revela um elevado grau de ajustamento dos indicadores e também mostra que o esforço inovador do setor 'Farmoquímicos/Farmacêuticos' (cluster 4), é, sob todos os aspectos, ímpar. Seus indicadores são, significativamente, superiores, o que o isola dos demais setores da economia. Particularmente, no tocante ao indicador interatividade, 'Farmoquímicos' apresenta um desempenho 3 vezes superior à média nacional e à maioria dos outros setores.

A elevada interatividade, utilização de recursos de financiamento públicos e presença de $\mathrm{P} \& \mathrm{D}$ interna, bem como a quase totalidade de empresas com gastos inovativos posicionam o setor em um cluster isolado e são compatíveis com os resultados das pesquisas internacionais desenvolvidas por Klevorick et al. (1995), Cockburn e Henderson (1998), Cohen; Nelson; Walsh (2002) e Fagerberg; Mowery; Verspagen (2008).

Particularmente, Cohen; Nelson; Walsh (2002) destacam que a indústria farmacêutica é uma anomalia em muitas dimensões. Não há outro setor no qual a pesquisa pública em ciência básica é tão relevante e o conhecimento de consumidores e outras manufaturas sejam menos importantes para a P\&D interna, o que sugere que o modelo linear pode caracterizar melhor o processo de inovação nesse setor que nos outros.

${ }^{10}$ Os dados completos da análise de variância (ANOVA) podem ser verificados em Silva (2011). 
Tabela 2 - Análise de Cluster II: Esforços inovativos

\begin{tabular}{|c|c|c|c|c|c|c|c|}
\hline \multirow[b]{2}{*}{$\frac{\grave{\Phi}}{\frac{\Phi}{\mathcal{O}}}$} & \multirow[b]{2}{*}{ Setores } & \multicolumn{4}{|c|}{$\%$ de empresas com } & \multirow[b]{2}{*}{$\begin{array}{l}\% \text { da receita } \\
\text { gasto em } \\
\text { atividades } \\
\text { inovativas }\end{array}$} & \multirow[b]{2}{*}{$\frac{\overline{\bar{d}}}{\overline{\underline{s}}}$} \\
\hline & & $\begin{array}{l}\text { gastos em } \\
\text { atividades } \\
\text { inovativas }\end{array}$ & $\begin{array}{l}\text { utilização } \\
\text { de recursos } \\
\text { públicos }\end{array}$ & $\begin{array}{c}\text { atividades } \\
\text { internas e } \\
\text { contínuas } \\
\text { de P\&D }\end{array}$ & $\begin{array}{l}\text { relações de } \\
\text { cooperação }\end{array}$ & & \\
\hline \multirow{4}{*}{-} & Outros equipamentos de transporte & 55,2 & 11,7 & 8,7 & 17,9 & 5,1 & $\ll$ \\
\hline & Celulose, papel e prods. de papel & 63,5 & 15,7 & 6,3 & 12,9 & 2,2 & 0 \\
\hline & Couros & 66,5 & 12,1 & 5,6 & 4,6 & 2,3 & ○ \\
\hline & Média & 61,8 & 13,1 & 6,9 & 11,8 & 3,2 & \\
\hline \multirow{14}{*}{$\sim$} & Metalurgia básica & 73,6 & 17,7 & 7,3 & 8,7 & 2,6 & $\varangle$ \\
\hline & Produtos de madeira & 66,6 & 29,9 & 0,9 & 14,5 & 3,0 & 0 \\
\hline & Confecção e acessórios & 71,6 & 19,9 & 1,8 & 7,6 & 1,8 & 0 \\
\hline & Prods. de minerais não-metálicos & 75,6 & 21,4 & 2,0 & 8,3 & 2,4 & 0 \\
\hline & Produtos têxteis & 78,4 & 13,6 & 3,4 & 6,9 & 2,5 & 0 \\
\hline & $\begin{array}{l}\text { Prods. de borracha e de material } \\
\text { plástico }\end{array}$ & 79,0 & 22,3 & 12,7 & 12,4 & 2,9 & 0 \\
\hline & $\begin{array}{l}\text { Man., rep. e inst. de máquinas e } \\
\text { equipamentos }\end{array}$ & 85,6 & 19,4 & 0,8 & 10,4 & 1,5 & 0 \\
\hline & Máquinas e equipamentos & 85,6 & 25,2 & 12,6 & 13,9 & 3,0 & 0 \\
\hline & Produtos de metal & 87,6 & 23,0 & 5,9 & 7,3 & 2,9 & 0 \\
\hline & Móveis e indústrias diversas & 88,4 & 27,9 & 6,5 & 9,5 & 3,2 & 0 \\
\hline & $\begin{array}{l}\text { Impressão e reprodução de } \\
\text { gravações }\end{array}$ & 89,9 & 33,1 & 1,3 & 7,8 & 4,4 & 0 \\
\hline & Alimentos e bebidas & 81,4 & 23,2 & 5,7 & 11,2 & 2,1 & 0 \\
\hline & $\begin{array}{l}\text { Veículos automotores, reboques e } \\
\text { carrocerias }\end{array}$ & 93,8 & 16,9 & 10,9 & 13,3 & 3,5 & ○ \\
\hline & Média & 81,3 & 22,6 & 5,5 & 10,1 & 2,8 & \\
\hline \multirow{6}{*}{ m } & Produtos do fumo & 93,9 & 12,2 & 36,6 & 18,3 & 1,5 & $\varangle$ \\
\hline & $\begin{array}{l}\text { Coque, ref. de petróleo e } \\
\text { biocombustíveis }\end{array}$ & 75,8 & 22,2 & 20,9 & 10,3 & 1,4 & $\infty$ \\
\hline & Químicos & 80,0 & 29,1 & 28,9 & 10,2 & 2,5 & $\infty$ \\
\hline & $\begin{array}{l}\text { Equips. de informática, prods. } \\
\text { eletrônicos e ópticos }\end{array}$ & 88,4 & 31,5 & 31,2 & 16,8 & 3,3 & o \\
\hline & $\begin{array}{l}\text { Máquinas, aparelhos e materiais } \\
\text { elétricos }\end{array}$ & 90,8 & 29,7 & 19,5 & 8,7 & 2,6 & ○ \\
\hline & Média & 85,8 & 25,0 & 27,4 & 12,8 & 2,3 & \\
\hline$\forall$ & Farmoquímicos e farmacêuticos & 95,3 & 38,7 & 35,4 & 35,3 & 4,9 & $\infty$ \\
\hline Indú & stria de transformação & 80,3 & 22,6 & 12,0 & 12,1 & 2,8 & \\
\hline \multicolumn{2}{|c|}{ R-quadrado } & & & & \multicolumn{3}{|c|}{0,9252} \\
\hline
\end{tabular}

Fonte: IBGE, PINTEC 2008, (elaboração própria). 
Um indicador que merece destaque isolado é o percentual da receita gasto com atividades inovativas pelo setor de 'Fabricação de outros equipamentos de transporte'. Com dispêndios de $5,1 \%$ o setor destaca-se com o maior volume de gastos de toda a indústria de transformação nacional e, ao mesmo tempo, apresenta a menor proporção de empresas com atividades inovativas, o que pode ser explicado pela presença de 'Fabricantes de aeronaves', grupo de alta intensidade tecnológica, num setor que, no geral, é composto por indústrias de baixa ou média intensidade e, considerando que o mercado de aeronaves possui características estruturais, competitivas e tecnológicas muito diferenciadas, sua agregação ao setor acaba por deturpar o comportamento dos indicadores setoriais.

Outro destaque é a correlação positiva entre gastos em atividades inovativas, absorção de recursos públicos e relações cooperativas. No geral, os setores em que é maior a proporção de empresas com gastos inovativos é também maior a utilização de recursos públicos e a existência de relações interativas. Por fim, é necessário salientar que a competência relacional da indústria nacional é muito baixa, e mesmo entre as empresas inovadoras, grupo no qual é suposto que tal competência seja maior, as relações de cooperação estão presentes, em média, em apenas 12\% das empresas.

Os traços distintivos do cluster 1 são a baixa proporção de empresas com gastos em atividades inovativas e a reduzida utilização de recursos públicos para financiamento destas atividades. No geral, o cluster apresenta grande homogeneidade entre seus componentes, com exceção do comportamento interativo de 'Couro e calçados' e o volume de receita despendido com as atividades inovativas por 'Outros equipamentos de transporte', volume este que torna a média de gastos do cluster superior ao da média da indústria de transformação. Sob a perspectiva da estrutura e desempenho, o cluster l é composto por setores com elevada propensão exportadora.

O agrupamento 2, por sua vez, tem o maior número de componentes da análise e, no geral, seus indicadores de esforços inovativos estão próximos da média nacional, e é média a intensidade tecnológica e a utilização de recursos públicos, conquanto a presença de atividades internas de $\mathrm{P} \& \mathrm{D}$ e o grau de interatividade sejam, para a maioria dos setores, muito inferiores à média. Aqui merece destaque a presença de setores de média-alta intensidade tecnológica 
como 'Veículos' e 'Máquinas e equipamentos', assim como o elevado volume de gastos $(4,4 \%$ da receita) em atividades inovativas pelo setor de 'Impressão', que representa um setor de baixa intensidade tecnológica e, portanto, apresenta um comportamento atípico para os padrões internacionais.

Como será visto em análise subsequente, o elevado volume de gastos inovativos pelo setor de 'Impressão' decorre da aquisição de softwares, o que é possível intuir aqui através da comparação entre os elevados gastos e a extremamente reduzida atividade interna de $\mathrm{P} \& \mathrm{D}$. A presença de 'Veículos', por sua vez, pode ser explicada pela hegemonia das multinacionais no setor e pela tendência destas, conforme Zucoloto (2004) e Quadros et al. (2002) concentrarem suas atividades de P\&D nos seus países de origem e, portanto, apresentarem fraco esforço inovativo em suas filiais. Logo, apesar de ser significativo o número de empresas com gastos em $\mathrm{P} \& \mathrm{D}$, as atividades internas de $\mathrm{P} \& \mathrm{D}$ e o esforço interativo são reduzidos, uma vez que as atividades inovativas estão restritas à adaptação de inovações desenvolvidas em solo estrangeiro.

Constituído por 5 setores, o cluster 3 possui a maioria de seus indicadores de esforços inovativos acima da média da indústria de transformação, exceção feita à intensidade dos esforços. Sobressai o fato de este ser um cluster formado por setores de elevada presença de P\&D interna, ser o segundo cluster mais interativo e ter características econômicas e tecnológicas difusas.

\subsubsection{Resultados dos Esforços Inovativos}

Por resultado do esforço tecnológico entende-se a introdução de produtos ou processos novos ou substancialmente aprimorados, ou seja, a inovação propriamente dita. Quando estes produtos ou processos são novos apenas para a empresa representam uma difusão; quando são novos para o mercado nacional representam inovações efetivas; e quando novos para o mercado mundial são consideradas inovações radicais. Assim, foram construídos 5 indicadores de esforço inovativo, quais sejam, taxa efetiva de inovação, inovações efetivas de produto, inovações efetivas de processo, inovações radicais de produto e inovações radicais de processo, cujo grau de ajustamento é muito elevado e explicam mais de $97 \%$ da variância interclusters. 
A Tabela 3 contempla a análise de cluster dos resultados do esforço inovativo da indústria nacional. Em primeiro lugar, destaca-se o fato de, com apenas duas exceções significativas ('Produtos de madeira', e 'Coque, petróleo e biocombustíveis', ambos posicionados no cluster 2), nos demais setores as inovações de produto ocorrem em maior volume que as inovações de processo. Outro destaque é o fato de as inovações efetivas ocorrerem em número significativamente baixo na maioria dos setores. Portanto, a difusão muito mais que a inovação caracteriza os SSI's nacionais, o que é compatível com o esperado para países de SI's imaturos, conforme Viotti (2002), Malerba e Nelson (2010).

O cluster 1 é constituído por: 4 setores de baixa intensidade tecnológica e reduzido esforço inovativo, conforme visto na análise anterior. Para todos os indicadores, a média do cluster e de seus componentes é inferior ao da indústria nacional. Em síntese, seus resultados inovativos são muito baixos e há no cluster apenas uma ligeira vantagem das inovações de produto sobre as de processo. São baixos também o grau de concentração de mercado e a produtividade da mão de obra e, à exceção de 'Couro e Calçados', a propensão exportadora.

Composto por setores de média baixa ou baixa intensidade tecnológica, o cluster 2 tem resultados inovativos muito próximos aos da média nacional e, quanto aos indicadores de estrutura e desempenho, 60\% deles estão no cluster C caracterizado pelas empresas de pequeno porte, baixa concentração de mercado, baixa produtividade e média propensão exportadora. Merece destaque o fato de 'Coque, petróleo e bicombustíveis' apresentar significativa proeminência das inovações de processo, o que é esperado de um setor 'Intensivo em escala', segundo Pavitt (1984).

No terceiro cluster estão reunidos setores que, no geral, apresentam desempenho bastante superior à média da indústria nacional. Simultaneamente, também os congrega a expressiva vantagem das inovações de produto sobre as de processo e o significativo, para os parâmetros nacionais, número de empresas com inovações radicais. 
Tabela 3 - Análise de Cluster III: Resultados do esforço inovativo

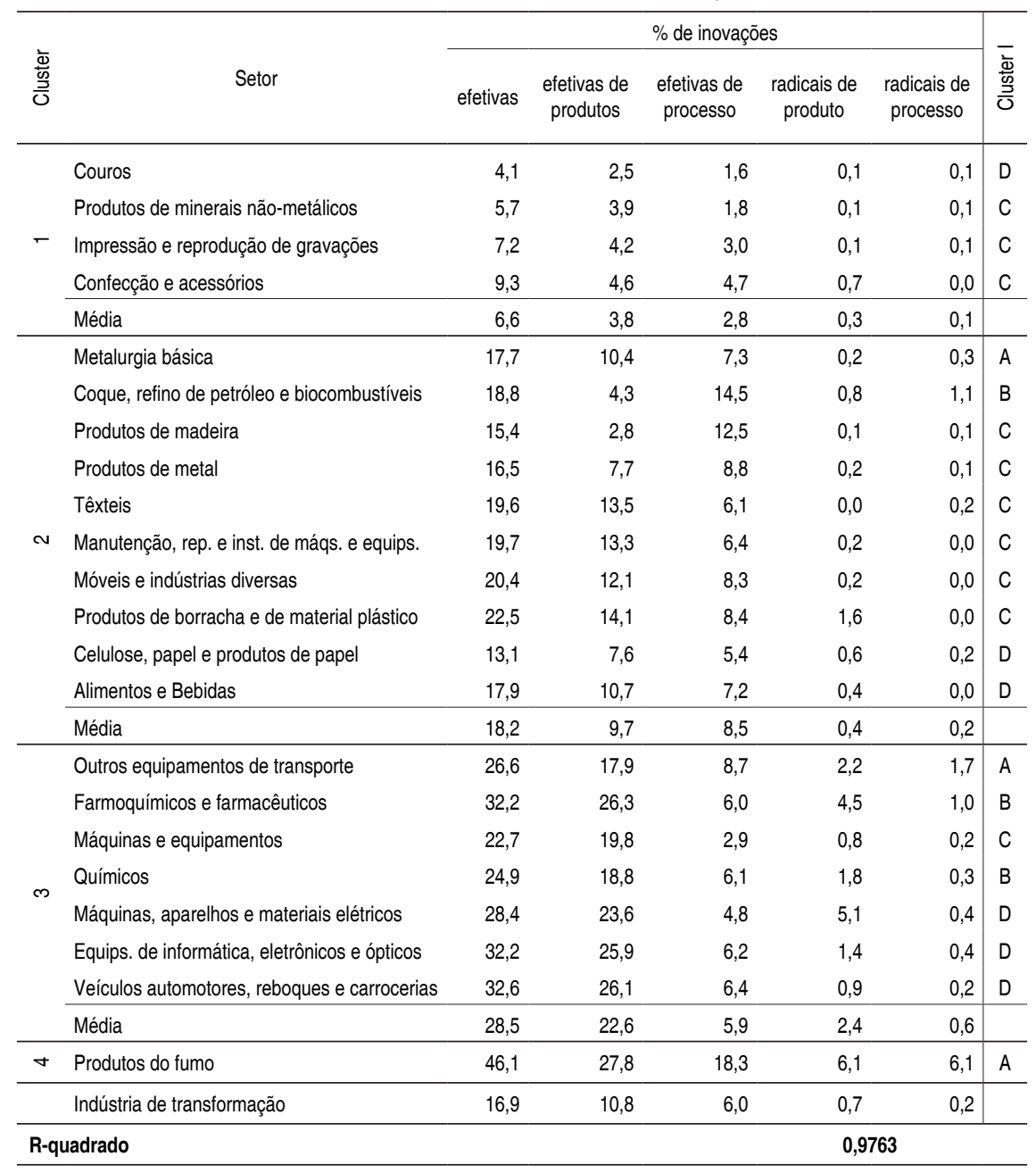

Fonte: IBGE, PINTEC 2008, (elaboração própria).

Chama atenção o fato de 'Veículos' apresentarem desempenho superior ao de 'Farmoquímicos e farmacêuticos', grupo de elevados esforços inovativos conforme demonstrado na análise anterior. No entanto, se forem observadas as inovações radicais, o desempenho de 'Farmoquímicos' só é menor que o de 'Máquinas, aparelhos e materiais elétricos' e 'Fumo', todos esses setores de elevados esforços. 
O cluster 3 possui representantes de todos os clusters de estrutura e desempenho. No entanto, mais de $57 \%$ deles, são do grupo D caracterizado pela alta propensão exportadora e, considerando também a presença do grupo A (muito alta propensão), é possível então afirmar que a propensão exportadora é um traço distintivo deste cluster.

Os resultados inovativos do setor de 'Fumo' são, em todos os aspectos, muito superiores aos da média da indústria de transformação e de todos os outros setores individualmente, o que o posiciona num cluster isolado. Tal fato, o elevado desempenho inovativo, diverge das pesquisas internacionais, no entanto, é similar ao apontado por outras análises da indústria nacional como as realizadas por Castro (2010), Campos e Ruiz (2009) e Zucoloto e Toneto Júnior (2005).

\subsubsection{Fontes de Informação}

O processo inovativo pressupõe a absorção do conhecimento gerado dentro e fora da empresa; neste sentido, a PINTEC identifica 11 fontes de conhecimento externas e 2 internas que, em última instância, determinam a capacidade absortiva das empresas. Assim, ao especificar as fontes de informação que consideram relevantes, as empresas revelam a origem e a forma de absorção do conhecimento utilizado no processo inovativo e o grau de abertura para absorção do conhecimento gerado intra e extramuros.

A análise de cluster referente à relevância atribuída pelas empresas às distintas fontes de informação é apresentada na tabela 4 , onde pode ser observado que, no geral, os setores utilizam, com relativa intensidade, todas as diferentes fontes de informação e que a intensificação da utilização de uma delas implica em intensificação de todas as outras. Do que resulta que há pouca diferenciação entre os clusters e ocasionou a formação de um número maior deles (6 no total). Com um R-quadrado geral superior a $68,5 \%$ é possível afirmar que a ajustabilidade dos indicadores é satisfatória para definição dos agrupamentos setoriais. 
O cluster 1 distingue-se pela baixa relevância atribuída a todas as fontes de informação. Composto por 5 setores de baixa densidade tecnológica, o agrupamento apresenta todos os indicadores abaixo da média da indústria de transformação e, particularmente, com relação às fontes internas muito inferior ao dos outros clusters. Outro traço distintivo do cluster 1 é a elevada relevância conferida a 'Fornecedores' e 'Concorrentes'. Tal característica sugere que, mais que nos outros setores, o aprendizado se dá através de spillovers interindustriais e interações com outras indústrias (Malerba, 1992). Quanto aos indicadores de estrutura e desempenho, todos os componentes do cluster 1 situam-se nas aglomerações C e D. São, portanto, setores com empresas de tamanho pequeno ou médio, situadas em mercados de baixa ou média concentração e produtividade, mas com propensão exportadora média ou alta. Características idênticas às dos clusters 2 e 3.

Apesar de também reunir setores para os quais é baixa a importância da maioria das fontes de informação, o cluster 2 diferencia-se pela elevada relevância atribuída a 'Redes informatizadas', 'Consultorias' e 'Clientes', bem como pelo fato de a significância de 'Concorrentes' como fonte de informação ser a menor da indústria nacional. Sobressai também a baixa importância conferida a 'Fornecedores', o que também foi apontado, no caso de 'Celulose', por Campos (2005) e Castro (2010).

O cluster 3 é constituído por indústrias que, com exceção de 'Veículos', assim como os componentes dos clusters 1 e 2, posicionaram-se nos agrupamentos de menor desempenho inovativo na análise realizada na seção anterior. Portanto, também não surpreende a baixa relevância atribuída pelo cluster às diferentes fontes de conhecimento, nem o destaque do setor de 'Veículos' para a P\&D interna, mas é surpreendente a pequena importância atribuída por um setor de média tecnologia, 'Veículos', à maioria das fontes externas de informação. Comportamento que, conforme visto anteriormente, pode ser explicado pelo predomínio de empresas multinacionais no setor. Outro destaque no cluster 3 e em toda a indústria de transformação nacional é a 'Metalurgia' em função da alta relevância atribuída às universidades como fonte de informação. 
Tabela 4 - Análise de cluster IV: Fontes relevantes de informação

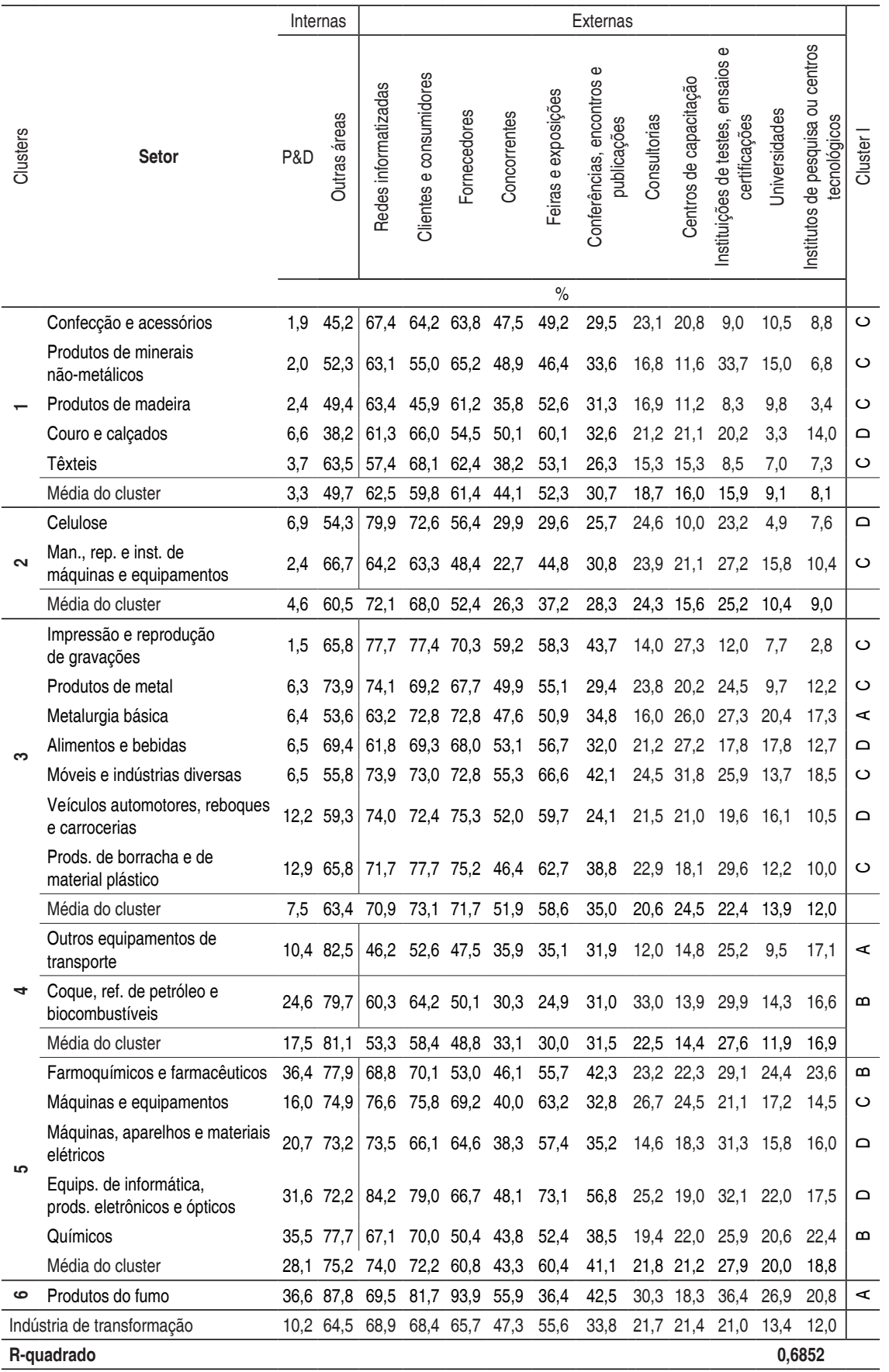

Fonte: IBGE, PINTEC 2008 (elaboração própria). 
A maioria dos indicadores de fontes de informação do cluster 4 posiciona-se próximo da média da indústria de transformação. Como características diferenciadoras, o agrupamento apresenta a mais baixa importância atribuída a 'Fornecedores', 'Concorrentes', 'Clientes', 'Redes informatizadas' e 'Feiras e exposições' e uma elevada importância dada a 'Outras áreas da empresa', o que permite inferir que o modelo de aprendizado típico do cluster é o "aprender fazendo" (Malerba, 1992) e seu grau de autonomia tecnológica é elevado (Ruiz e Bhawan, 2010).

O cluster 5 possui indicadores significativamente superiores à média nacional, e é formado por setores de média-alta ou alta tecnologia, e compõem o cluster de segundo melhor desempenho inovativo. As fontes internas de conhecimento são consideradas relevantes por $100 \%$ das empresas, e é expressiva a atribuição de relevância à infraestrutura tecnológica (universidades, institutos de pesquisa, centros de capacitação e instituições de testes), o que é compatível com o esperado para setores baseados em ciência.

O elevado desempenho de 'Fumo' novamente o isola no cluster 6. Em indicadores como P\&D interna e interações com universidades, a relevância atribuída pelo setor é respectivamente 3,6 e 2,1 vezes a média da indústria de transformação, o que é uma explicação para o seu desempenho inovativo apresentado na Tabela 3 e também uma demonstração da capacidade absortiva do setor.

Dada a elevada relevância atribuída a todas as fontes de informação e, em particular às fontes internas, é possível afirmar que os clusters 5 e 6 "aprendem pesquisando" (P\&D), "aprendem fazendo" (outras áreas de empresa), "aprendem usando ou através de transbordamentos interindustriais" (fornecedores e concorrentes) e "aprendem interagindo" com outras fontes externas (Malerba, 1992).

\subsubsection{Fontes de Inovação}

Fontes de inovação dizem respeito aos gastos inovativos das empresas, gastos estes que podem ser destinados a atividades internas ou aquisições externas e revelam o padrão de aprendizado das empresas. Representando, as fontes internas formas ativas de aprendizado e 
produção do conhecimento e as externas formas passivas através das quais as empresas "aprendem usando" recursos e produtos elaborados extramuros (Malerba, 1992). A relação entre estas duas fontes determina o grau de autonomia tecnológica. ${ }^{11}$

$\mathrm{Na}$ Tabela 5 estão expostas as fontes de inovação utilizadas pela indústria de transformação nacional. O R-quadrado de $83 \%$ confere elevada aceitação estatística para os 5 clusters propostos. O primeiro deles é formado por setores de média-baixa ou baixa tecnologia, de propensão exportadora média, alta ou muito alta, baixa autonomia tecnológica e nos quais o gasto médio com 'aquisição de máquinas e equipamentos' e os gastos em fontes externas representam, respectivamente, $75 \%$ e $80 \%$ dos gastos atribuídos às atividades inovativas. Outra característica relevante é o baixo volume de gastos em atividades internas de P\&D, elas não chegam a $8 \%$ do total das fontes de inovação. Portanto, é possível afirmar que no cluster 1 as empresas "aprendem usando" e este aprendizado é passivo.

Merece destaque o fato de a 'Metalurgia' apresentar gasto em 'projeto industrial e preparação técnica' superior à média nacional. Segundo Campos (2005), a variável 'projeto industrial' aproximase daquilo que a literatura internacional intitula como 'Desenho e Engenharia', portanto, faz sentido que, conforme verificado em estudos internacionais como Pavitt (1984), Archibugi; Cesaratto; Sirilli (1991) e nacionais como o próprio Campos (2005) e Zucoloto (2004), um setor 'Intensivo em escala' tenha como fonte de inovação relevante as engenharias de produção e processo. A autonomia tecnológica do agrupamento 2 é inferior à média da indústria de transformação, os gastos com 'máquinas e equipamentos' são superiores a $59 \%$ do total de gastos e as atividades internas de P\&D, apesar de superiores à do cluster 1 , são baixas. Além disso, merece ser destacado que os gastos com aquisição de 'Conhecimento externo' é o maior da indústria, o que somado às outras aquisições caracteriza o processo de aprendizagem do setor, igualmente com o cluster 1 , como exógeno.

Surpreende a presença de 'Químicos' no cluster 2, pois este é um setor de média-alta tecnologia (do qual é esperada uma elevada autonomia tecnológica) e do mesmo estar, segundo a Tabela 2, entre os

${ }^{11}$ Dado que a 'Autonomia tecnológica' resulta do balanceamento entre todos os componentes das fontes de inovação, optou-se por calculá-la após a definição dos clusters. 
setores de maiores esforços tecnológicos. No entanto, tal posicionamento é semelhante ao identificado por Campos (2005) e Zucoloto (2004) na análise da PINTEC 2000, e decorre da significativa participação das aquisições de 'Máquinas e equipamentos' no seu conjunto de gastos inovativos.

Tabela 5 - Análise de cluster V: Fontes de inovação

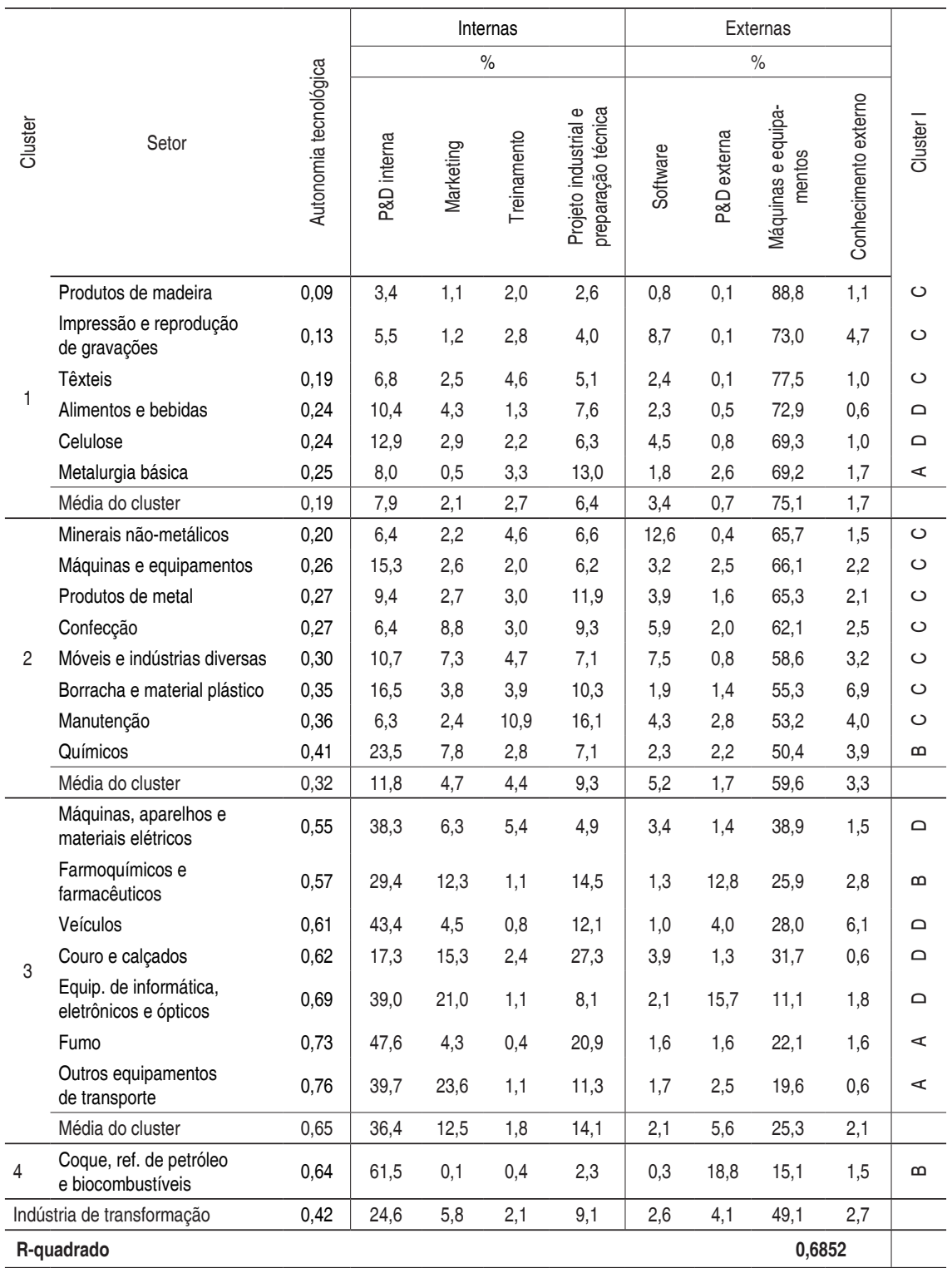

Fonte: IBGE, PINTEC 2008, (elaboração própria). 
O terceiro agrupamento reúne os setores cuja autonomia tecnológica é a maior de toda a indústria de transformação nacional, o que decorre, fundamentalmente, dos elevados gastos em P\&D interna $(36,4 \%)$ e do baixo, para o padrão nacional, dispêndio em 'máquinas e equipamentos' $(25,3 \%)$. Adicionalmente, são elevados os gastos em $\mathrm{D} \& \mathrm{E}$ $(14,1 \%)$, o que, novamente, é compatível com o esperado para um cluster composto, em sua maioria por 'Intensivos em escala'. Além disso, a estrutura econômica é difusa, mas aproximadamente $86 \%$ do cluster são setores com alta ou muito alta propensão exportadora.

Assim como nas aglomerações realizadas anteriormente, a análise de fontes de inovação revela a existência de um setor que tem comportamento tão distinto dos outros setores que provoca o estabelecimento de um cluster com um único elemento. Neste caso, o setor de 'Coque, petróleo e biocombustíveis' é o outlier que, em virtude da atipicidade de conduta, particularmente em P\&D interna $(61,5 \%)$, duas vezes e meia a média da indústria de transformação e aquisição de máquinas e equipamentos $(15,1 \%)$ apenas 0,31 da média isola-se dos setores restantes. Tal resultado possibilita definir o processo de aprendizagem do setor como "aprender pesquisando" e determina seu elevado grau de autonomia tecnológica.

\subsubsection{Interatividade}

A avaliação do grau de interatividade setorial é pertinente com a percepção de que as relações interativas ampliam a capacidade inovativa e revelam o poder absortivo das empresas, além de configurarem e fortalecerem os SSI's. Neste sentido, espera-se de setores que demonstrem maior competência relacional que apresentem também um maior desempenho inovativo e estejam inseridos em SSI's mais robustos.

Na PINTEC são entendidas como relações de cooperação aquelas que envolvem o desenvolvimento de projetos conjuntos de $\mathrm{P} \& \mathrm{D}$ ou outros projetos inovativos entre a empresa e agentes da infraestrutura tecnológica ou participantes de sua cadeia produtiva. 
Na Tabela 6 é apresentada a relevância atribuída pelas empresas às suas diferentes relações de cooperação. Em primeiro lugar, é importante salientar que, conforme visto na Tabela 2, a competência relacional da indústria de transformação nacional é muito baixa e, em média, apenas 12\% das empresas inovadoras estabelecem relações cooperativas. Em segundo lugar, destaca-se que para a maioria dos setores (há apenas 4 exceções) as relações com 'fornecedores' ou 'clientes' são identificadas como as de maior contribuição para o processo inovativo.

No cluster 1 estão setores para os quais a relações interativas são consideradas de pouca contribuição para as inovações, mas as relações com universidades e institutos de pesquisa recebem avaliação superior à média da indústria de transformação e, considerando o pressuposto de maior interatividade e maior desempenho inovativo, surpreende que 'Químicos' esteja no cluster 1 . No entanto, como visto anteriormente (Tabela 2), o grau de interatividade de 'Químicos' é inferior à média da indústria nacional, fato para o qual a possível explicação é a participação do capital estrangeiro no setor e a concentração dos investimentos em $\mathrm{P} \& \mathrm{D}$, realizados por este capital, nos seus países de origem (Zucoloto, 2004).

'Produtos de minerais não metálicos' é outro componente do cluster 1 que desperta curiosidade, pois apesar do baixo grau de interatividade, baixo desempenho inovativo e de ser definido como um setor 'Dominado por fornecedores', o mesmo considera as relações com 'universidades e institutos de pesquisa' mais relevantes que as interações com 'fornecedores'.

O cluster 2 é formado por setores que compartilham a baixa interatividade (conforme Tabela 2), a mais elevada relevância atribuída a 'fornecedores' e a mais baixa a 'universidades e institutos de pesquisa'. Além desse fator, o cluster 2 também é caracterizado pelo baixo desempenho inovativo e o pequeno ou médio tamanho, produtividade e concentração, adicionalmente, a elevada relevância de 'fornecedores', somada a não importância das outras relações, sugere que os setores do cluster comportam-se como "Dominados por fornecedores", conforme Leiponen e Drejer (2007) e corresponde (com exceção do setor de 'Celulose') à classificação realizada por Campos (2005) e Castro (2010). 
Tabela 6 - Análise de cluster VI: Interatividade

\begin{tabular}{|c|c|c|c|c|c|c|c|c|c|}
\hline \multirow[t]{2}{*}{ 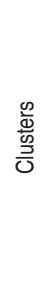 } & \multirow[t]{2}{*}{ Setor } & 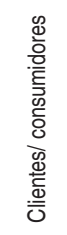 & 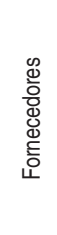 & 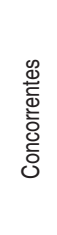 & 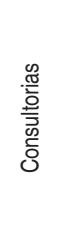 & 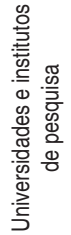 & 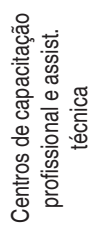 & 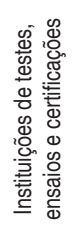 & 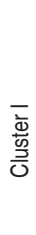 \\
\hline & & \multicolumn{7}{|c|}{$\%$} & \\
\hline \multirow{5}{*}{-} & Coque, ref. de petróleo e biocombustíveis & 16,6 & 62,9 & 14,9 & 37,1 & 52,0 & 22,3 & 22,3 & 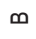 \\
\hline & Químicos & 42,1 & 51,9 & 6,5 & 20,5 & 20,5 & 12,7 & 28,6 & $\infty$ \\
\hline & Minerais não metálicos & 15,8 & 41,7 & 10,4 & 4,2 & 54,2 & 7,4 & 9,5 & 0 \\
\hline & Produtos de madeira & 22,8 & 43,9 & 23,2 & 25,6 & 32,6 & 35,0 & 20,2 & 口 \\
\hline & Média do cluster & 24,3 & 50,1 & 13,7 & 21,8 & 39,8 & 19,3 & 20,1 & \\
\hline \multirow{7}{*}{$\sim$} & Têxteis & 40,1 & 87,6 & 29,4 & 46,5 & 11,4 & 31,7 & 30,5 & 0 \\
\hline & Impressão e reprodução de gravações & 39,8 & 99,1 & 0,9 & 0,0 & 1,9 & 38,0 & 0,0 & 0 \\
\hline & Produtos de metal & 50,5 & 83,1 & 10,7 & 22,5 & 16,4 & 14,5 & 22,1 & 0 \\
\hline & Móveis e Indústrias diversas & 54,1 & 90,5 & 2,6 & 33,3 & 15,6 & 32,8 & 36,9 & 0 \\
\hline & Alimentos e bebidas & 33,7 & 77,1 & 28,4 & 21,8 & 26,9 & 29,7 & 14,9 & 口 \\
\hline & Celulose, papel e produtos de papel & 38,7 & 95,7 & 6,8 & 29,8 & 12,6 & 27,2 & 14,5 & 口 \\
\hline & Média do cluster & 42,8 & 88,8 & 13,1 & 25,6 & 14,2 & 29,0 & 19,8 & \\
\hline \multirow{5}{*}{ m } & Farmoquímicos e farmacêuticos & 50,5 & 68,2 & 26,0 & 52,6 & 52,6 & 17,7 & 41,1 & $\infty$ \\
\hline & Confecção e acessórios & 41,2 & 55,2 & 38,5 & 51,3 & 49,7 & 57,4 & 33,9 & 0 \\
\hline & $\begin{array}{l}\text { Equips. de informática, eletrônicos e } \\
\text { ópticos }\end{array}$ & 47,6 & 65,8 & 9,8 & 26,7 & 53,8 & 21,5 & 34,0 & 口 \\
\hline & Máquinas, aparelhos e materiais elétricos & 46,7 & 76,9 & 6,5 & 28,6 & 44,8 & 24,8 & 47,2 & 口 \\
\hline & Média do cluster & 46,5 & 66,5 & 20,2 & 39,8 & 50,2 & 30,4 & 39,0 & \\
\hline \multirow{7}{*}{$\forall$} & Produtos do fumo & 100,0 & 66,7 & 0,0 & 33,3 & 66,7 & 33,3 & 33,3 & $\ll$ \\
\hline & Metalurgia básica & 63,3 & 50,3 & 8,7 & 25,0 & 42,8 & 16,5 & 16,6 & $\varangle$ \\
\hline & Outros equipamentos de transporte & 60,7 & 42,6 & 0,0 & 10,8 & 21,6 & 6,2 & 4,6 & $\varangle$ \\
\hline & Prod. de borracha e de material plástico & 71,7 & 44,5 & 13,0 & 19,2 & 16,3 & 36,1 & 22,0 & 0 \\
\hline & Máquinas e equipamentos & 57,3 & 57,3 & 5,2 & 36,4 & 15,4 & 14,7 & 11,1 & 0 \\
\hline & $\begin{array}{l}\text { Veículos automotores, reboques e } \\
\text { carrocerias }\end{array}$ & 70,8 & 70,9 & 6,7 & 24,0 & 22,0 & 19,9 & 34,1 & 口 \\
\hline & Média do cluster & 70,6 & 55,4 & 5,6 & 24,8 & 30,8 & 21,1 & 20,3 & \\
\hline 10 & $\begin{array}{l}\text { Man., rep. e inst. de máquinas e equi- } \\
\text { pamentos }\end{array}$ & 16,5 & 34,0 & 5,9 & 57,5 & 71,9 & 7,5 & 66,3 & 0 \\
\hline 6 & Couro e calçados & 17,0 & 44,1 & 3,9 & 67,1 & 9,4 & 11,2 & 9,6 & 0 \\
\hline \multicolumn{2}{|c|}{ Indústria de transformação } & 44,7 & 64,9 & 15,5 & 29,4 & 29,4 & 26,7 & 23,3 & \\
\hline \multicolumn{2}{|c|}{ R-quadrado } & & & & & & \multicolumn{3}{|c|}{0,6452} \\
\hline
\end{tabular}

Fonte: IBGE, PINTEC 2008, (elaboração própria). 
O traço distintivo do cluster 3 é o maior equilíbrio da avaliação das diferentes relações cooperativas. A relevância de 'fornecedores' é pouco superior à média nacional, mas a avaliação das outras relações, particularmente, da infraestrutura tecnológica, é substancialmente superior à média. A presença de 'Confecções', indústria BDT num cluster em que todos os outros elementos são de alta densidade, deve-se ao seu comportamento atípico no tocante à avaliação das relações cooperativas. Em primeiro lugar, a relevância de 'fornecedores' é menor que a de 'centros de capacitação'. Em segundo, a avaliação das outras relações é significativamente superior à média. Para Alves (2008), tal comportamento é explicado pelo esforço de qualificação profissional decorrente da reestruturação produtiva pela qual vem passando o setor.

Ainda sobre o cluster 3 , a elevada relevância conferida às relações com todas as fontes externas sugere o modelo de aprendizado através da interação e, no caso de 'Confecções', as relações cooperativas mais substituem que complementam as atividades internas de pesquisa, uma vez que, conforme visto na análise de 'Fontes de inovação', a autonomia tecnológica é baixa no setor.

O cluster 4 é constituído por setores que estão aglutinados em função da maior significância das relações com 'clientes' e da menor significância de 'concorrentes'. As relações com a infraestrutura tecnológica é próxima da média da indústria de transformação. Adicionalmente, a multiplicidade de relações com boa avaliação define o cluster como o de maior competência relacional; sob esta perspectiva, 'Fumo' destaca-se como o setor mais competente e de comportamento mais homogêneo, pois todas as empresas consideram relevantes as relações com 'clientes' e todas consideram irrelevantes as relações com 'concorrentes'. Vale lembrar que o setor detém a segunda maior taxa de interação da indústria. O comportamento interativo diferenciado de 'Fumo' também foi detectado por Kato et al. (2008), que destacaram o fato de a maioria das relações de cooperação do setor serem estabelecidas com 'clientes' do exterior.

Outra curiosidade do cluster 4 é que, apesar de superior à média nacional, é baixa a relevância atribuída pela 'Metalurgia' às 'universidades e instituto de pesquisa'. O fato é intrigante, dada a elevada importância atribuída pelo setor às 'universidades' como fonte de informação (conforme Tabela 4). 
Em função da elevada diferenciação de seus comportamentos com relação aos demais, os setores de 'Manutenção' e 'Couro' foram isolados em 2 clusters diferentes e comungam avaliações muito abaixo da média para 'clientes', 'fornecedores' e 'concorrentes', e muito acima da média para 'consultorias'. No entanto, com relação às interações com a infraestrutura tecnológica, apresentam comportamentos díspares. Enquanto 'Manutenção' atribui a maior relevância de toda a indústria nacional para as relações com 'universidades e institutos de pesquisa' e 'instituições de testes e ensaios', em ambos os casos a avaliação do setor é quase 3 vezes superior à média, o setor de 'Couro' situa-se no extremo oposto com um grau de relevância muito abaixo da média nacional para toda a infraestrutura tecnológica. O desempenho inovativo dos dois setores é significativamente diferenciado também. 'Couro' detém a taxa mais baixa de inovatividade da indústria, enquanto 'Manutenção' apresenta taxa pouco superior à média nacional. Por fim, o R-quadrado de 64\% apesar de baixo, em comparação aos resultados apresentados pelas demais análises, permite afirmar que o ajustamento dos clusters propostos é satisfatório.

\subsubsection{Trajetórias Tecnológicas}

Por trajetória tecnológica entende-se a direção assumida pelo desenvolvimento tecnológico, o padrão do progresso técnico cujos limites são determinados pelo contexto concorrencial, organizacional e tecnológico no qual as firmas estão inseridas. Em síntese, a trajetória é definida pelas motivações e impactos das inovações, e resulta das possibilidades tecno-científicas disponíveis para as firmas e da capacidade de apropriação dos benefícios gerados pela inovação (Klevorick et al., 1995 e Nelson e Winter, 1982). Neste sentido, a PINTEC considera 11 diferentes tipos de impactos, reunidos em 4 grupos, quais sejam, produto, mercado, processos produtivos, aspectos relacionados ao meio ambiente, saúde e segurança, ou ao enquadramento em regulamentações e normas.

Na Tabela 7 é apresentado o resultado da análise de cluster para o foco da trajetória tecnológica. Chama a atenção, em primeiro lugar, o fato de, para a maioria dos setores, a 'manutenção de mercado' e a 'qualidade dos produtos' estarem entre os impactos mais relevantes. 
Do que resulta que estas são as trajetórias dominantes na indústria nacional. Em segundo lugar, que a proximidade entre os focos seja grande, o que faz com que as diferenças entre os clusters sejam pequenas e explica a baixa significância (R-quadrado de inferior a 60\%) dos indicadores de trajetória para explicar as diferenças intersetoriais, fato que também foi verificado por Castro (2010). Por fim, a relevância da 'redução de impactos' para um número significativo de setores, o que em geral é acompanhado pelo destaque simultâneo do foco em 'enquadramento às normas' e pode ser explicado pelas preocupações ambientais na economia contemporânea e nos decorrentes instrumentos de controle impostos pela sociedade a determinados setores. Caso evidente de 'Fumo', 'Veículos', 'Coque, petróleo e biocombustíveis', 'Produtos de madeira' e 'Móveis'.

O setor de 'Coque, petróleo e biocombustíveis' é o outlier da análise de trajetória, o que decorre, em primeiro lugar, de suas trajetórias dominantes concentrarem-se em processo e, em segundo lugar, de ser este o setor que atribui a maior relevância da indústria nacional ao foco de 'Redução de custos'. Outra conduta diferenciada do setor é a elevada relevância atribuída ao foco de 'Redução de impactos'. No tocante aos focos associados ao produto e ao mercado, o setor situa-se abaixo da média nacional.

Os setores que compõem o cluster 2 apresentam uma ligeira proeminência do foco de 'Redução de impactos ambientais, de saúde e segurança' sobre os demais e, exceto este indicador, todos os outros são inferiores à média da indústria. Dentre os componentes do cluster, 'Manutenção' merece destaque em função da também marcante presença da trajetória tecnológica orientada pelo 'aumento da capacidade produtiva'.

O cluster 3 é constituído por 'setores de baixa (os seis primeiros), média-alta e alta tecnologia (os dois últimos) e para os quais a trajetória tecnológica é dominada por 'manutenção de mercado' e 'aumento da qualidade dos produtos' que apresentam pequena vantagem sobre as demais. No geral, predominam as trajetórias orientadas por mercado e produto e, particularmente, nos setores de 'Informática' e 'Máquinas e materiais elétricos' há um domínio do foco em 'qualidade dos produtos', resultado que é semelhante ao identificado por Campos (2005). 
No entanto, assim como os outros componentes do cluster, a relevância dos diferentes focos situa-se abaixo da média nacional. Com relação aos indicadores de estrutura e desempenho, predomina no cluster 3 o agrupamento ' $D$ ', cuja concentração, tamanho e produtividade são médias e a propensão exportadora é alta.

No cluster 4 estão setores de baixa (os três primeiros) e média-alta tecnologia (os dois últimos) e cuja trajetória tecnológica também é dominada por 'manutenção de mercado' e qualidade de produtos'. No entanto, o que merece destaque no cluster é a ascendência dos focos de 'Redução de impactos ambientais, de saúde e segurança' 'Redução de custos' e 'Enquadramento às normas'. Compõem o agrupamento os setores para os quais tais orientações têm maior proeminência na indústria nacional. Especificamente, no caso do setor de 'Fumo' a 'Redução de impactos' define a trajetória tecnológica setorial.

Já o cluster 5 é formado por setores que se aglutinam por identificarem significativa relevância em praticamente todas as alternativas de trajetória com maior destaque para os focos de processo ('Flexibilidade' e Capacidade produtiva') e mercado ('Abertura de novos mercados', 'Ampliação e manutenção da participação no mercado').

Finalmente, é importante destacar que, como mencionado anteriormente, as diferenças entre os clusters de trajetória são pequenas e, somado a isto, exceto no terceiro cluster, as características de estrutura e desempenho são também difusas, o que restringe o estabelecimento de um perfil dominante para os mesmos. 


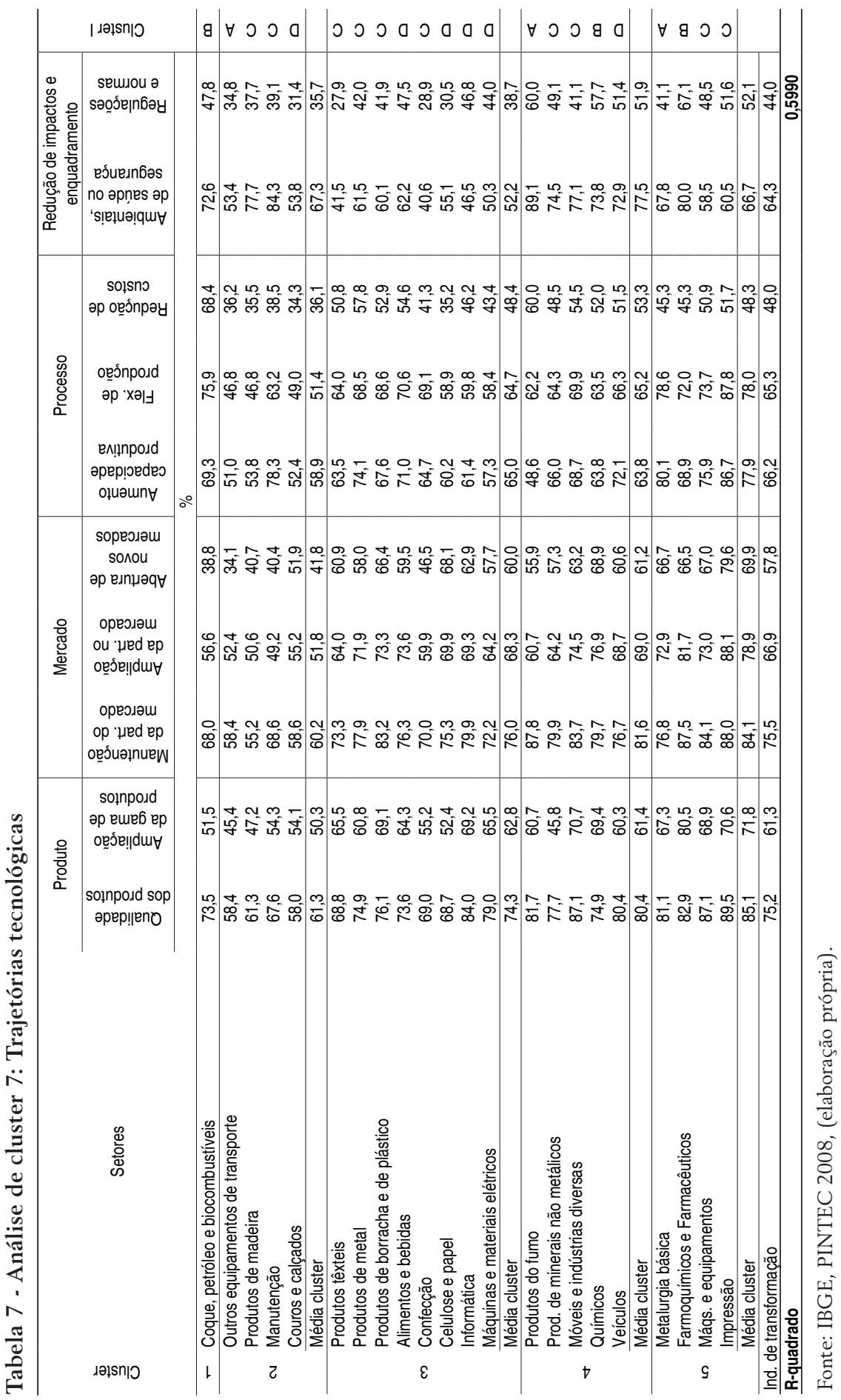




\section{Padrões Setoriais de Inovação}

Partindo das aglomerações propostas nas etapas anteriores, a presente seção busca avaliar a aderência da taxonomia de Pavitt (1984) e de proposições elementares da EENS (características econômicas e interatividade) no comportamento inovativo da indústria de transformação brasileira. Para tanto, foram destacadas, dos perfis traçados anteriormente, as variáveis distintivas dos 4 tipos propostos por Keith Pavitt e adicionou-se outro conjunto de variáveis que se acredita sejam relevantes na determinação das condutas setoriais. Em primeiro lugar, a tipologia pavittiana é construída a partir das diferenças intersetoriais no que diz respeito ao tamanho relativo das firmas, das fontes de informação e inovação por elas utilizadas, do tipo predominante de inovações implementadas e dos esforços inovativos empregados. O que resulta em 4 categorias setoriais distintas, quais sejam, 'Dominados por fornecedores', 'Intensivos em escala', 'Fornecedores especializados' e 'Baseados em ciência'.

Resumidamente, os setores 'Dominados por fornecedores' são compostos por firmas de pequeno porte, nas quais as inovações decorrem das mudanças introduzidas por fornecedores e, consequentemente, os esforços inovativos internos são reduzidos e concentrados em processo. Os 'Intensivos em escala' são constituídos por firmas grandes nas quais predominam as inovações de processo e cujas fontes de inovação são os fornecedores e as atividades internas de P\&D. Os 'Fornecedores especializados' distinguem-se pelo pequeno porte das firmas e pela elevada presença dos clientes como fonte das inovações que são também complementadas pelas fontes internas e concentram-se em produto. Por fim, os setores 'Baseados em ciência' são formados por empresas grandes, com elevados esforços inovativos internos e resultados equivalentes em produto e processo.

Em segundo lugar, a taxonomia pavittiana foi complementada por duas outras variáveis, concernentes com os princípios da EENS, quais sejam: o grau de interatividade e o desempenho exportador das firmas. Adicionalmente, utilizou-se como parâmetro qualitativo de diferenciação das fontes de informação utilizadas a avaliação relativa às universidades. A Tabela 8 sintetiza o resultado do esforço de padronização setorial do comportamento inovador da indústria nacional. Inicialmente, sobressai a significativa convergência dos distintos setores da indústria nacional à taxonomia pavittiana e às proposições da EENS. Com apenas duas exceções, 'Produtos de minerais não metálicos' e 'Produtos de metal', os demais setores, em virtude de 
suas afinidades de conduta e estrutura econômica, convergiram para os agrupamentos estabelecidos pelas proposições teóricas.A análise do conjunto da indústria nacional revela a estreita relação entre interatividade, relevância atribuída à infraestrutura tecnológica e o grau de inovatividade. Com apenas três exceções, 'Máquinas, aparelhos e materiais elétricos' (setor em que a interatividade é baixa, mas a inovatividade e a relevância são altas), 'Celulose' e 'Produtos de madeira' (a interatividade é média-alta e inovatividade e relevância são baixas), nos demais interatividade e inovatividade são confluentes, confirmando os dados da Economic Commission for Latin America and the Caribbean - ECLAC (2008), segundo os quais, no Brasil, $94,5 \%$ das empresas que participam de redes cooperativas são empresas inovadoras, ao mesmo tempo, entre as empresas não interativas a taxa de inovação cai para $40,2 \%$.

Na segunda coluna da Tabela 8 pode ser verificado o posicionamento dos respectivos setores nas análises empreendidas em seções anteriores. Nela observa-se que a composição dos clusters foi um instrumento robusto na definição dos padrões setoriais, em que pese o fato dos setores não manterem um comportamento harmônico e, consequentemente, não estarem posicionados sempre numa mesma combinação face às variáveis de análise selecionadas.Os 3 últimos agrupamentos 'Fornecedores especializados', 'Baseados em ciência' e 'Intensivos em escala' congregam os setores que apresentam as maiores interatividades, relevância atribuída à infraestrutura tecnológica (universidades) e presença de P\&D interna, o que os aproxima e explica a quase unânime presença da pesquisa e da interação como formas de aprendizado.

A categoria 'Dominados por fornecedores' é constituída por 'Produtos de minerais não metálicos', 'Confecção', 'Impressão', 'Produtos de madeira', 'Têxteis', 'Produtos de metal', 'Móveis e indústrias diversas', 'Manutenção', 'Produtos de borracha e plástico' e 'Couro e calçados. Apesar de o grupo ser grande, há uma significativa homogeneidade entre os seus componentes no tocante ao tamanho, taxa de inovatividade, esforços e resultados inovativos e propensão exportadora que variam entre média e baixa. Por outro lado, é elevada a presença dos fornecedores como fonte de informação e a proporção dos gastos inovativos em 'Máquinas e equipamentos', consequentemente, é baixa a autonomia tecnológica, o que é outra característica distintiva do grupo. 
A convergência de 'Couro e calçados' para o grupo de 'Dominados por fornecedores' decorre de seus baixos esforços inovativos, interatividade e inovatividade e é compatível com o que foi verificado em análises internacionais (Pavitt, 1984 e Archibugi et al., 1991) e nacionais (Campos, 2005 e Castro, 2010). No entanto, sua elevada propensão exportadora e autonomia tecnológica destoam do restante do grupo e divergem da proposição da EENS acerca da convergência entre desempenho exportador, interatividade e esforços inovativos, bem como do predomínio absoluto dos gastos em 'Máquinas e equipamentos'. Como verificado na Tabela 5, no período 2006-2008, a maior parcela $(31,7 \%)$ dos gastos inovativos do setor foi destinada a essa modalidade, no entanto, os elevados dispêndios relativos com 'Projeto industrial e preparação técnica' (27,3\%) e 'Marketing' $(15,3 \%)$ acabaram por determinar a autonomia tecnológica do setor. Vale destacar que os gastos relativos de 'Couro e calçados' com 'Projeto industrial' é o mais alto da indústria nacional.

'Fornecedores especializados' é composto por 'Outros equipamentos de transportes' e 'Máquinas e equipamentos', e caracterizado pela significativa presença de P\&D interna, estreito relacionamento com clientes e fornecedores, e o foco das atividades inovativas na ampliação de desempenho de seus produtos. A classificação dos 2 setores que compõem o grupo é coincidente com a realizada por Campos (2005) e com a taxonomia de Pavitt. Além dessas características, este é o aglomerado com as mais elevadas taxas de intensidade de esforços tecnológicos e interatividade, o que explica a presença do aprendizado por interação. O terceiro agrupamento é 'Baseados em ciência', categoria composta por 'Químicos', 'Farmoquímicos e Farmacêuticos', 'Informática, eletrônicos e ópticos' e 'Máquinas, aparelhos e materiais elétricos'. As características distintivas do grupo são a elevada performance dos indicadores de esforços e resultados inovativos e a combinação das diferentes fontes de inovação e formas de aprendizado. Sua composição e propriedades identificadas estão em consonância com o esperado pela taxonomia e os resultados verificados por outras pesquisas nacionais (Castro, 2010; Campos, 2005 e Zucoloto, 2004) e internacionais (Pavitt, 1984; Archibugi; Cesaratto; Sirilli, 1991 e Malerba, 1992).

Tendo em vista a padronização setorial de inovação aqui proposta, a sincronia dos elementos da categoria 'Baseados em ciência' entre si e com as proposições teóricas faz deste grupo o mais homogêneo entre os identificados no presente trabalho. A presença de 'Máquinas e equipamentos' e 'Software' entre os gastos inovativos é 
reduzida. Em contrapartida, os dispêndios com recursos extramuros concentram-se na obtenção de conhecimento tanto na forma de 'P\&D externa' quanto de 'Outros conhecimentos externos'. O foco das atividades inovativas está, fundamentalmente, em 'Produtos' e 'Mercados', mas para os setores 'Químico' e 'Farmoquímico e farmacêuticos' a trajetória também é determinada pela necessidade de 'Enquadramento' às normas e regulamentos e 'Redução de impactos' ambientais à saúde e segurança do trabalho. O que é compatível com a pesada regulação que incide sobre o setor e está em consonância com os resultados da análise empreendida por Campos (2005) e Castro (2010). Acrescido a isto, o processo de aprendizagem e inovação tem origem interna nas atividades de pesquisa (P\&D interna) que são complementadas pelas interações e aquisições de 'P\&D externa' e 'Outros conhecimentos' são, portanto, setores intensivos em P\&D conforme Cohen e Walsh (2000).

Quanto ao perfil econômico, o agrupamento é composto, em igual proporção, por setores caracterizados pelo médio ou grande porte (em conformidade com a taxonomia pavittiana), elevada ou média concentração, produtividade média ou muito alta e propensão exportadora baixa. A elevada correlação entre produtividade, concentração e taxa de inovatividade, bem como a baixa correlação entre inovatividade e propensão exportadora foram também constatadas por Gonçalves; Lemos; De Negri (2007) em análise do padrão estrutural das empresas inovadoras nacionais. No entanto, é interessante destacar que nos setores intensivos em $\mathrm{P} \& \mathrm{D}$ a distância entre os esforços realizados pelas empresas nacionais e internacionais é extremamente elevada. Segundo a análise de Zucoloto (2004) para o período de 1998-2000, os esforços médios em atividades internas de P\&D nos países da OCDE eram 4,33\% do valor da produção industrial enquanto no Brasil estes eram de 1,33\%. ${ }^{12}$ Especificamente em 'Químicos' e 'Farmoquímicos e Farmacêuticos' as diferenças chegavam a 5,7 e 10,8 vezes respectivamente. Some-se a isto o fato desses setores contarem com a infraestrutura científica mais robusta e SNI's maduros dos países desenvolvidos e é razoável supor que o esforço tecnológico das empresas brasileiras, apesar de elevado para os parâmetros locais, é insuficiente para eliminar o hiato tecnológico destes setores e, consequentemente, para garantir-lhes um desempenho exportador superior.

12 Apesar de os indicadores de gastos em atividades internas de P\&D não terem sido apontados no presente trabalho, não houve alteração significativa do comportamento dos setores 'Químicos' e 'Farmacêuticos e Farmoquímicos' no período 2006-2008, segundo os dados da PINTEC 2008. 


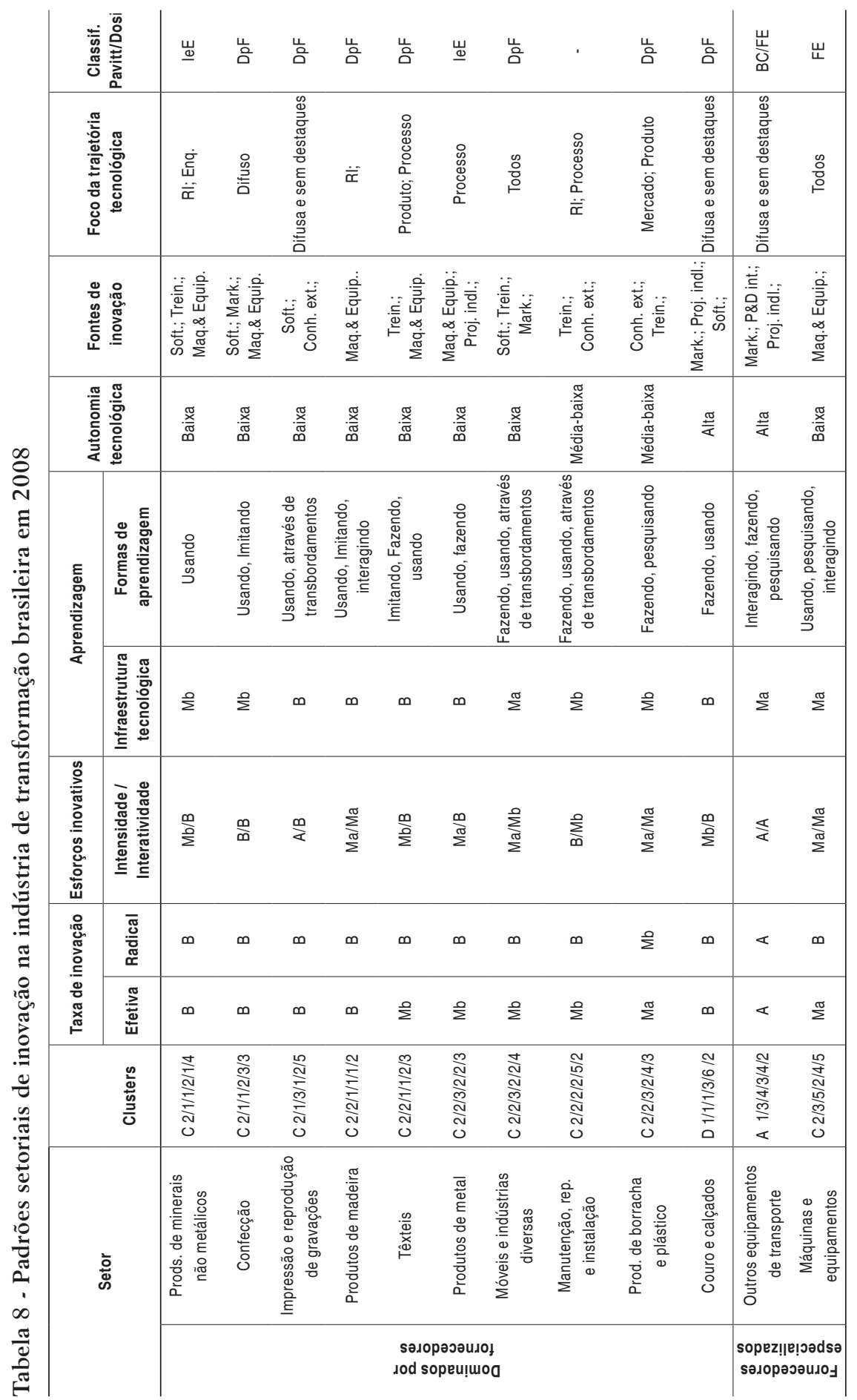




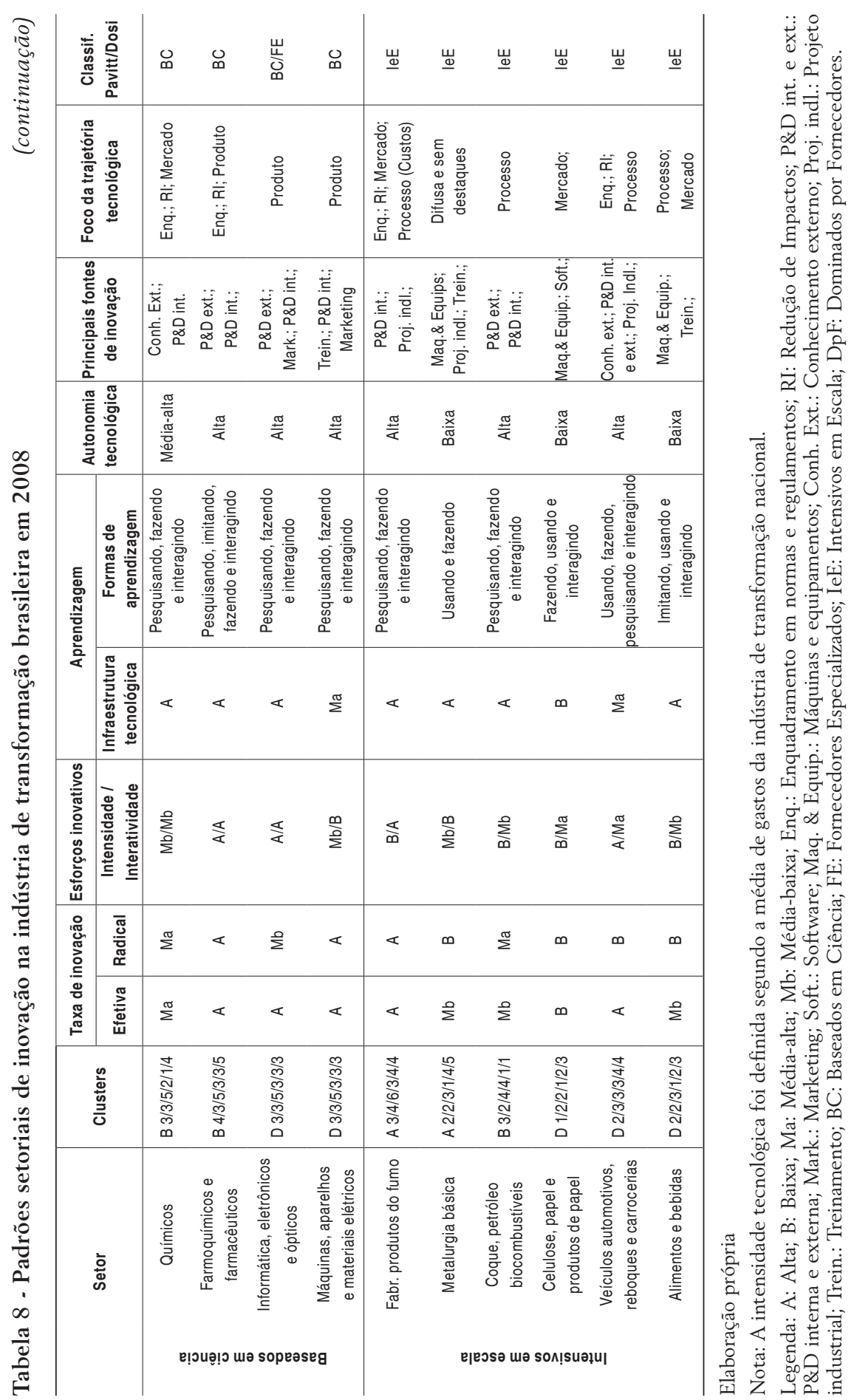


Por sua vez, nos setores de baixa e média intensidade tecnológica, a distância entre os investimentos realizados por empresas brasileiras e de países da OCDE é significativamente menor, no caso dos setores de 'Fumo' e 'Alimentos' a diferença é inferior a 0,07\% do valor da produção industrial, em favor dos países da OCDE, e em setores como o de 'Petróleo' e 'Celulose' os investimentos médios das empresas nacionais suplantam o de empresas dos países da OCDE em mais de 0,07 e 0,48\% respectivamente, conforme Zucoloto (2004). Em casos como estes o gap tecnológico é menor e as inovações podem ampliar a competitividade internacional do setor, bem como as exportações representarem um estímulo às inovações, o que explica a convergência dos indicadores de propensão exportadora e inovatividade no setor de 'Fumo' no presente estudo.

A categoria de 'Intensivos em escala' congrega os setores que, segundo Pavitt (1984), são fabricantes de produtos padronizados e bens duráveis de consumo, caracterizados pela presença de grandes empresas, predomínio das inovações de processo com objetivo na redução de custos e desenvolvimento próprio de novas tecnologias através de atividades internas de $\mathrm{P} \& \mathrm{D}$ e engenharias de processo e produção. Características que aglutinam 'Fumo', 'Metalurgia básica', 'Coque, petróleo e biocombustíveis', 'Celulose e Papel' 'Veículos' e 'Alimentos e bebidas' no quarto agrupamento da análise em curso.

A comparação dos agrupamentos 1 e 4 revela que a diferença entre estes é estabelecida pela intensidade dos esforços inovativos e pela substituição do foco em produto (grupo 1) pelo foco em processo (grupo 4). Adicionalmente, é maior no grupo 4 a presença de setores com maior propensão exportadora ('Fumo', 'Metalurgia básica', 'Veículos' e 'Alimentos e Bebidas'). Por outro lado, assim como no grupo 1 , o grupo 4 não tem surpresas quanto à sua composição e comportamento, e há uma expressiva relevância para os focos de 'Redução de impactos' e 'Enquadramento' o que, novamente, decorre dos controles públicos sobre emissão de poluentes, no caso de 'Veículos' e tabagismo, no caso de 'Fumo'.

A convergência dos setores posicionados na categoria de 'Intensivos em escala' foi estabelecida, fundamentalmente, pela proximidade das fontes de inovação, formas de aprendizado, trajetórias tecnológicas, interatividade e resultados inovativos e resultou no agrupamento, sob todos os aspectos, mais heterogêneo da presente aná- 
lise. Particularmente, nos casos da 'Celulose', Metalurgia básica' e 'Alimentos e Bebidas' é significativo o número de contatos entre si, ao mesmo tempo em que é pequeno o número de contatos com os outros componentes do agrupamento. O mesmo acontece com 'Couro e calçados' no grupo 'Dominados por Fornecedores'. Estes cinco setores têm em comum a baixa densidade tecnológica e a elevada propensão exportadora e merecem, em função da reduzida afinidade com os demais componentes de seus respectivos agrupamentos, algumas considerações.

\subsection{Desempenho dos Setores de Baixa Densidade Tecnológica e Elevada Propensão Exportadora na PINTEC}

Há, entre 'Couro', 'Celulose', 'Alimentos e bebidas' e 'Metalurgia básica' convergências de indicadores entre si e, simultaneamente, divergência de indicadores com os demais componentes de suas respectivas categorias. A tênue agregação desses setores às categorias assumidas pela taxonomia pavittiana é decorrente da conjunção de características inovativas peculiares, extraídas da PINTEC e de indicadores de estrutura e desempenho, que acabam enfraquecendo o enquadramento nas categorias assumidas. Nos demais casos, constata-se uma significativa aderência à taxonomia pavittiana e às proposições da EENS.

Os setores que apresentam baixa vinculação com os demais membros de seus respectivos agrupamentos têm em comum a baixa densidade tecnológica, o desempenho exportador que varia de alto a muito alto, a elevada concentração econômica, o pequeno esforço inovativo, as baixas inovatividade e interatividade ('Metalurgia', 'Alimentos e bebidas' e 'Couro'), a baixa autonomia tecnológica ('Metalurgia', 'Celulose' e 'Alimentos e bebidas') e a dispersão da trajetória tecnológica ('Metalurgia', 'Couro' e 'Alimentos e bebidas'). Adicionalmente, as simetrias entre estes setores refutam a hipótese de correlação positiva entre intensidade exportadora e inovatividade (Som; Dreher; Maloca, 2010; Laursen, 2008; Zucoloto e Toneto Júnior, 2005; Kannebley; Porto; Pazzelo, 2003; Van Dijk, 2002 e Freeman, 1982). 
Por sua vez, a indústria do 'Fumo' apresenta elevado desempenho exportador e inovativo, apesar de ser também um setor de baixa densidade tecnológica. A Tabela 9 sintetiza algumas características estruturais e inovativas destas 5 indústrias. Como pode ser verificado, no tocante aos indicadores de estrutura e desempenho, 'Fumo' diferencia-se dos demais setores exportadores de baixa densidade tecnológica em função da propensão exportadora muito superior (mais de 45\% da receita é oriunda das exportações), da concentração econômica muito elevada e do número muito pequeno de empresas em atuação. Do ponto de vista tecnológico a atuação, e resultados do setor tabagista são também muito superiores e, para alguns indicadores, semelhante aos setores de alta densidade tecnológica, o que é incompatível com os demais setores 'Intensivos em escala'.

Tabela 9 - Estrutura e perfil inovativo dos setores de baixa densidade tecnológica e elevada performance exportadora

\begin{tabular}{|c|c|c|c|c|c|c|c|}
\hline Setor & $\begin{array}{l}\text { Número de } \\
\text { empresas }\end{array}$ & Concentração & $\begin{array}{c}\text { Exportações } \\
\text { (\% da receita } \\
\text { líquida) }\end{array}$ & $\begin{array}{c}\text { Inovações } \\
\text { efetivas }\end{array}$ & $\begin{array}{l}\text { Densidade } \\
\text { tecnológica / } \\
\text { Interatividade }\end{array}$ & $\begin{array}{c}\text { Importância da } \\
\text { infraestrutura } \\
\text { tecnológica }\end{array}$ & $\begin{array}{l}\text { Autonomia } \\
\text { tecnológica }\end{array}$ \\
\hline Fumo & 62 & 83,1 & 45,6 & 12,2 & $B / A$ & A & A \\
\hline Metalurgia & 1.675 & 32,3 & 27,1 & 7,0 & $\mathrm{Mb} / \mathrm{B}$ & A & B \\
\hline $\begin{array}{l}\text { Alimentos } \\
\text { e bebidas }\end{array}$ & 12.613 & 27,5 & 19,3 & 6,8 & $\mathrm{~B} / \mathrm{Mb}$ & A & B \\
\hline Couros & 5.111 & 23,9 & 30,1 & 1,5 & $\mathrm{Mb} / \mathrm{B}$ & B & A \\
\hline Celulose & 2.138 & 17,4 & 21,7 & 4,6 & $\mathrm{~B} / \mathrm{Ma}$ & B & B \\
\hline
\end{tabular}

Elaboração própria.

Nota: A densidade tecnológica foi definida segundo a média de gastos da indústria de transformação nacional.

Legenda: A: Alta; B: Baixa; Mb: Média-baixa.

Somado à elevada concentração, o número pequeno de empresas no setor de 'Fumo', na medida em que reduz disparidades intrasetoriais do comportamento, permite extrair um retrato mais fiel do comportamento setorial. No caso dos demais setores, particularmente, na 'Metalurgia básica' em função de ser este o setor de segunda maior concentração econômica e elevada dispersão intrasetorial, o elevado número de empresas com pequena relevância econômica termina por mascarar o padrão e os resultados inovativos do grupo de empresas que determinam o comportamento de busca e a trajetória tecnológica e econômica do setor. Portanto, os resultados apresentados por de 'Fumo' e 'Metalurgia básica' indicam que o tamanho da empresa tem importância na determinação de seu comportamento inovativo, 
o que reaproxima o desempenho destes setores das proposições de Schumpeter (1943) e da EENS Pavitt (1984), Cohen; Florida; Goe (1994) e Archibugi; Cesaratto; Sirilli (1991).

A dificuldade para obter um perfil fidedigno destes setores e um padrão inovativo mais linear pode ser atribuída às suas idiossincrasias estruturais, tecnológicas e econômicas, aos imperativos concorrenciais do comércio internacional e aos limites da taxonomia para absorver diferenças intrasetoriais (Som; Dreher; Maloca, 2010; Laursen, 2008 e Archibugi, 2001).

Por estas razões, tentativas anteriores de identificação dos padrões setoriais da indústria brasileira já acusaram a relutância de ajuste destes setores à taxonomia pavittiana. Em Campos (2005), 'Celulose' configura-se como 'Fornecedor especializado', 'Fumo' como 'Intensivo em escala' e 'Alimentos e bebidas' como 'Dominados por fornecedores'; já em Castro (2010), 'Celulose' é classificado como 'Intensivo em escala', 'Fumo' não se ajusta a nenhuma categoria, 'Alimentos e bebidas' é também classificado como 'Dominados por fornecedores', o que difere da classificação proposta por Pavitt (1984) e Dosi; Pavitt; Soete (1990).

No caso da 'Metalurgia', particularmente, no tocante ao foco da trajetória tecnológica o setor apresenta comportamento similar aos setores 'Máquinas e equipamentos' e 'Impressão' ('Fornecedor especializado' e 'Dominado por fornecedores', respectivamente). Quanto aos resultados inovativos e esforços tecnológicos, o setor está bastante próximo dos componentes de 'Dominados por fornecedores', no entanto, apesar da baixa interatividade geral e do baixo desempenho inovativo, o setor apresenta alto volume de relações cooperativas com a infraestrutura tecnológica, o que o assemelha aos 'Intensivos em P\&D'. Somado a isto, a 'Metalurgia' também apresenta um perfil econômico que o distingue dos 'Dominados por fornecedores', especialmente quanto à sua muito alta propensão exportadora e concentração e tamanho médio. Por outro lado, segundo a tipologia de Pavitt (1984), a 'Metalurgia básica' está adequadamente alinhada com os setores 'Intensivos em escala', no entanto, seu esforço e desempenho inovativo é inferior, e sua trajetória destoa dos outros componentes deste agrupamento. Tamm; Reiljan; Seppo (2007), numa avaliação do padrão setorial inovativo das indústrias da Estônia, também identificaram a ambiguidade de comportamento 
da 'Metalurgia básica', particularmente no tocante ao regime tecnológico, o que resultou na classificação do setor como 'Intensivo em escala' e 'Dominado por fornecedores' simultaneamente.

No tocante à heterogeneidade intrasetorial, Som, Dreher, Maloca (2010) analisaram o comportamento de empresas alemãs que não realizam gastos em $\mathrm{P} \& \mathrm{D}$ e identificaram em todos os setores, mesmo naqueles de alta densidade tecnológica, a existência de um número significativo de empresas e uma grande dispersão de padrões inovativos. Entre os setores de baixa densidade tecnológica, 58,1\% das empresas não realizaram qualquer dispêndio em $P \& D$ no ano de 2009; já entre os setores de média e alta densidade a parcela de empresas é de $27,0 \%$ e 16,8\% respectivamente. Uma distribuição que é próxima da apresentada quando o recorte é o número de empregos, qual seja entre as empresas com até 49 empregados, 62,0\% não realizaram gastos em $\mathrm{P} \& \mathrm{D}$, quando o número de empregos varia entre 50 e 249, elas são 43,4\%; e finalmente para empresas com mais de 250 empregados, o número de empresas cai para $16,5 \%$. O que indica que, em todos os setores, a presença de gastos em $P \& D$ é também determinada pelo porte das empresas.

Em síntese, a baixa aderência dos setores de 'Fumo', 'Couro', 'Celulose', 'Alimentos e bebidas" e 'Metalurgia básica' à taxonomia decorre da conjugação de heterogeneidade intrasetorial, peculiaridades das características econômicas e do perfil inovativo elaborado a partir dos dados setoriais da PINTEC. Particularmente, destaca-se o fato de nestes setores as exportações representarem parcela significativa da receita e, em sendo setores maduros e de baixa densidade tecnológica, haver um menor gap tecnológico, o que estimula as inovações. Adicionalmente, o grande número de empresas com baixa expressividade econômica dificulta a obtenção de um perfil condizente com o comportamento das empresas que determinam a trajetória setorial.

\section{Considerações Finais}

A análise dos padrões setoriais de inovação da indústria de transformação brasileira revela adequação à taxonomia de Pavitt. Com apenas duas exceções ('Produtos de minerais não-metálicos' e 'Produtos de metal', ambos setores de baixa densidade tecnológica) o compor- 
tamento dos demais setores (91\%) da indústria é compatível com a taxonomia proposta. No entanto, o ajustamento de 4 outros setores BDT ('Couro', 'Celulose', 'Alimentos e bebidas"' e 'Metalurgia básica') aos seus respectivos tipos pavittianos é precário.

Além da baixa aderência à taxonomia, tais setores também se assemelham por outros aspectos, quais sejam: elevadas propensão exportadora e concentração econômica e as baixas inovatividade e esforço inovativo.

Dada a aderência da maioria das indústrias, o descolamento dos setores BDT não invalida as proposições teóricas sintetizadas na taxonomia, mas sugere que a identificação dos padrões setoriais de inovação deva considerar as peculiaridades estruturais das indústrias, particularmente, naquelas caracterizadas pela conjugação de concentração econômica e elevado número de empresas. Nestas, o comportamento de um pequeno número de firmas é que determina o desempenho econômico e tecnológico do setor. No entanto, este comportamento é diluído quando o perfil setorial é construído a partir de uma grande quantidade de empresas com baixa relevância econômica.

\section{Referências}

ALVES, Rozane. O setor confecções de vestuário e acessórios: estratégias competitivas. XLVI Congresso da Sociedade Brasileira de Economia, Administração e Sociologia Rural, 2008.

ARCHIBUGI, Daniele. Pavitt's taxonomy sixteen years on: A review article. In: Economics of Innovation and New Technology, Vol. 10, pp. 415-425, 2001.

ARCHIBUGI, Daniele; CESARATTO, Sergio and SIRILLI, Giorgio. Sources of innovative activities and industrial organization in Italy. Research Policy, v.20, p. 299-313, 1991.

BUSSAB, Wilton de Oliveira; MIAZAKI, Edina Shizue e ANDRADE, Dalton Francisco. Introdução à Análise de Agrupamentos. Associação Brasileira de Estatística. ABE. $9^{\circ}$ Simpósio Nacional de Probabilidade e Estatística. São Paulo, julho, 1990.CAMPOS, Bruno C. Padrões Setoriais de Inovação na Indústria Brasileira em 2000. Dissertação de Mestrado. Rio de Janeiro, Universidade Federal Fluminense. Disponível em <http://www.uff.br/cpgeconomia/novosite/arquivos/tese/2005-bruno_campos.pdf>. Acesso em 26/07/2011.

CAMPOS, Bruno C. e RUIZ, Ana U. Padrões Setoriais de Inovação na Indústria Brasileira. Revista Brasileira de Inovação, Rio de Janeiro (RJ), 8 (1), p.167-210, janeiro/junho, 2009.

CASTRO, Daniela Fernandes de. Padrões Setoriais da Inovação Tecnológica na Indústria Brasileira: Uma Análise de Cluster a Partir da Pintec, 2010.

COCKBURN, Ian M. and HENDERSON, Rebecca M. Absorptive Capacity, Coauthoring Behavior, and the Organization of Research in Drug Discovery. Journal of Industrial Economics, Volume 46, pages 157-182, 1998.

Estud. Econ., São Paulo, vol. 44, n.2, p. 277-321, abr.-jun. 2014 
COHEN, Wesley M. and WALSH, John P. Public research, patents and implications for industrial R\&D in the drug, biotechnology, semiconductor and computer industries. In C.W. Wessner, ed., Capitalizing on New Needs and New Opportunities: Government-Industry Partnerships in Biotechnology and Information Technologies, Washington, D.C.: National Academy Press, 2001. pp 223-243, 2000.

COHEN, Wesley M.; FLORIDA, Richard and GOE, W. Richard. University-Industry Research Centers in the United States, (Pittsburgh: Carnegie Mellon University), 1994.

COHEN, Wesley M.; NELSON, Richard R. and WALSH, John P. Protecting their intellectual assets: Appropriability conditions and why U.S. Manufacturing firms patent (or not). Cambridge, Mass., National Bureau of Economic Research, 2000.

COHEN, Wesley M.; NELSON, Richard R. and WALSH, John P. Links and impacts: the influence of public $R \& D$ on industrial research. Management Science, v. 48, n. 1, pp. 1-23, 2002.

DOSI, Giovanni; PAVITT, Keith; SOETE, Luc. The Economics of Technical Change and International Trade. Londres: Harvester Wheatsheaf, 1990.

ECLAC. Structural Change and Productivity Growth -20 Years Late, Old Problems, New Opportunities. United Nations, Santiago, Chile, 2008.

FAGERBERG, Jan; MOWERY, David C and VERSPAGEN, Bart. Innovation-systems, path-dependency and policy: The co-evolution of science, technology and innovation policy and industrial structure in a small, resource-based economy. DIME Working paper 2008.1 in the series on Dynamics of Knowledge Accumulation, Competitiveness, Regional Cohesion and Economic Policies (DIME Working Package 3.1) June, 2008.

FLORIDA, Richard and COHEN, Wesley M. Engine or infrastructure? The university role in economic development. In Branscomb, L.M., Kodama, F., Florida, R. (Eds.). Industrializing Knowledge: University-Industry Linkage in Japan and the United States, The MIT Press, Boston, MA, 1999.

FREEMAN, Christopher. Technological infrastructure and international competitiveness. Industrial and Corporate Change, v. 13, n. 3, p.541-569, 1982.

GONÇALVES, Eduardo; LEMOS, Mauro. B. e DE NEGRI, João A. Determinantes do Esforço Inovador no Brasil. Anais do XXXV Encontro Nacional de Economia; ANPEC; Recife, 2007.

HAIR, Joseph F.; ANDERSON, Rolph E.; TATHAM, Ronald L., and BLACK, William C. Multivariate Data Analysis- Fifth Edition. New Jersey, Prentice Hall, 1998.

KANNEBLEY JR., Sérgio; PORTO, Gerciane S. e PAZZELO, Elaine T. Anais Encontro Nacional de Economia. Características das empresas inovadoras no Brasil: Uma análise empírica a partir da PINTEC, Porto Seguro. ANPEC, 2003. Disponível em: <http://www.anpec.org.br/encontro2003/ artigos/D49.pdf $>$. Acesso em 01 de abril de 2010. 2003.

KATO, Mayumi; GOBARA, Erika; ROSSONI, Caio; CUNHA, Luciano e KINDL, Sieglinde. Padrões de Cooperação Tecnológica entre Setores na Indústria Brasileira: Uma Análise Quantitativa dos Dados da PINTEC 2001-2003. RAI - Revista de Administração e Inovação, vol. 5, núm. 3, pp. 126-140, Universidade de São Paulo, São Paulo, 2008.

KLEVORICK, Alvin K., LEVIN, Richard C., NELSON, Richard R. and WINTER Sidney G. On the sources and significance of interindustry differences in technological opportunities. Research Policy 24:185-205, 1995.

LAURSEN. K. The effect of knowledge sources for export performance in manufacturing and services: Danish firm-level evidence. DRUID. Disponível em: <http://www.nupi.no/content/download/9191/96283/ file/Paper\%208.pdf>. Acesso em: 08/08/2011. 2008.

LEIPONEN, Aija and DREJER, Ina. What exactly are technological regimes? Intra-industry heterogeneity in the organization of innovation activities. Research Policy 36:1221-1238, 2007.

LEVIN, Richard C.; KLEVORICK, Alvin K.; NELSON, Richard R. and WINTER, Sidney G. Appropriating the Returns from Industrial R\&D. Brookings Papers on Economic Activity, 783-820, 1987.

MALERBA, Franco. Learning by firms and incremental technical change. The Economic Journal, v.102, n.413, p.845-859, Jul., 1992.

Estud. Econ., São Paulo, vol. 44, n.2, p. 277-321, abr-jun. 2014 
MALERBA, Franco. Sectoral systems of innovation and production. Research Policy 31: 247-264, 2002.

MALERBA, Franco and NELSON, Richard. Catching up in different sectoral system. Disponível em $<$ http://umconference.um.edu.my/upload/43-1/papers/198\%20FrancoMalerba_RichardNelson. pdf>. Acesso em 05/02/2011. 2010.

MANSFIELD, EDWIN, AND LEE, JEONG-YEON. THE MODERN UNIVERSITY: CONTRIBUTOR TO INDUSTRIAL INNOVATION AND RECIPIENT OF INDUSTRIAL R\&D SUPPORT. RESEARCH POLICY 25: 1047-1058, 1996.

NELSON, Richard R. e WINTER, Sidney G. Uma Teoria Evolucionária da Mudança Econômica. Campinas, Editora da UNICAMP, 2005. 1982.

PAVITT, Keith. Sectoral patterns of technical change: Towards taxonomy and a theory. Research Policy 13: 343-373, 1984.

PAVITT, Keith. Changing Patterns of Usefulness of University Research: Opportunities and Dangers Sectoral. Disponível em <http://www.merit.unu.edu/publications/papers/200210_pavitt.pdf>. Acesso em 26/07/2011. 2002.

QUADROS, Ruy; FURTADO, André; BERNARDES, Roberto e FRANCO, Eliane. Technological innovation in Brazilian industry: an assessment based on the São Paulo innovation survey. Technological Forecasting and Social Change, v. 67, p. 203-219, 2002.

RUIZ, Ana Urraca e BHAWAN, Renata. Diferenças de comportamento inovador entre empresas nacionais e estrangeiras no Brasil. Revista Brasileira de Inovação Rio de Janeiro (RJ), 9 (1), p. 29-68, janeiro/junho, 2010.

SCHUMPETER, Joseph A. Capitalism, Socialism and Democracy. G. Allen \& Unwin, Londres, 1976. 1943.

SILVA, Conceição de F. Indústria metalúrgica básica brasileira: perfil setorial, inovatividade e interatividade. Tese de doutorado. Campinas, UNICAMP, 2011. Disponível em http://www.bibliotecadigital. unicamp.br/document/?code=000840644\&fd=y. Acesso em 20/05/2012. 2011.

SOM, Oliver; DREHER Carsten and MALOCA Spomenka. Innovation patterns of non-R\&D performing firms in the German manufacturing industry. An evolutionary approach to heterogeneity in firms ' innovation strategy. International Schumpeter Society Conference 2010 on Innovation, Organisation, Sustainability and Crises. Aalborg, June 21-24, 2010.

TAMM, Dorel; REILJAN, Ele; and SEPPO, Marge. Is There Sector Specificity in the Cooperation Potential and Propensity to Innovate? The Evidence from Estonia. Majandusteaduse Seltsi II aastakonverents; Pärnu, 12.-13. jaanuar 2007. Disponível em $<$ http://www.emselts.ee/konverentsi/ EMS2007/Tamm_Reiljan_Seppo.pdf>.Acesso em 16/10/2011.2007.

VAN DIJK, Michiel. "The determinants of export performance in developing countries: the case of Indonesian Manufacturing”. Working Paper 02.01. Eindhoven Centre for Innovation Studies. Disponível em: <http://demo.uib.es/courses/econometrics/Exports.pdf>. Acesso em 21/10/2011. 2002.

VIOTTI, Eduardo B. National Learning Systems A new approach on technological change in late industrializing economies and evidences from the cases of Brazil and South Korea. Technological Forecasting \& Social Change, 69, 653-680, 2002.

ZUCOLOTO, Graziela F. Inovação Tecnológica na Indústria Brasileira: Uma Análise Setorial. Dissertação de Mestrado. São Paulo, USP, 2004. Disponível em: <http://www.teses.usp.br/teses/ disponiveis/12/12140/tde-30082004-161640/pt-br.php>. Acesso em 26/07/2011. 2004.

ZUCOLOTO, Graziela F. e TONETO JR., Rudinei. Esforço tecnológico da indústria de transformação brasileira uma comparação com países selecionados. Revista de Economia Contemporânea, Rio de Janeiro, 9(2): 337-365, mai./ago., 2005. 